OAK RIDGE

NATIONAL LABORATORY

ORNL/TM-2012/442

MANAGED BY UT-BATTELLE

FOR THE DEPARTMENT OF ENERGY

\title{
Power Harvesting Practices and Technology Gaps for Sensor Networks
}

\section{September 2012}

Prepared by

Dwight Clayton

William H. Andrews, Jr.

Roberto Lenarduzzi

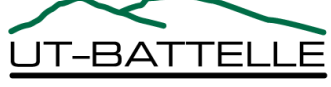

ORNL-27 (4-00) 


\title{
DOCUMENT AVAILABILITY
}

Reports produced after January 1, 1996, are generally available free via the U.S. Department of Energy (DOE) Information Bridge.

Web site http://www.osti.gov/bridge

Reports produced before January 1, 1996, may be purchased by members of the public from the following source.

\author{
National Technical Information Service \\ 5285 Port Royal Road \\ Springfield, VA 22161 \\ Telephone 703-605-6000 (1-800-553-6847) \\ TDD 703-487-4639 \\ Fax 703-605-6900 \\ E-mail info@ntis.gov \\ Web site http://www.ntis.gov/support/ordernowabout.htm
}

Reports are available to DOE employees, DOE contractors, Energy Technology Data Exchange (ETDE) representatives, and International Nuclear Information System (INIS) representatives from the following source.

Office of Scientific and Technical Information

P.O. Box 62

Oak Ridge, TN 37831

Telephone 865-576-8401

Fax 865-576-5728

E-mail reports@osti.gov

Web site http://www.osti.gov/contact.html

\begin{abstract}
This report was prepared as an account of work sponsored by an agency of the United States Government. Neither the United States Government nor any agency thereof, nor any of their employees, makes any warranty, express or implied, or assumes any legal liability or responsibility for the accuracy, completeness, or usefulness of any information, apparatus, product, or process disclosed, or represents that its use would not infringe privately owned rights. Reference herein to any specific commercial product, process, or service by trade name, trademark, manufacturer, or otherwise, does not necessarily constitute or imply its endorsement, recommendation, or favoring by the United States Government or any agency thereof. The views and opinions of authors expressed herein do not necessarily state or reflect those of the United States Government or any agency thereof.
\end{abstract}




\title{
Power Harvesting Practices and Technology Gaps for Sensor Networks
}

\author{
Dwight Clayton \\ William H. Andrews, Jr. \\ Roberto Lenarduzzi
}

Date Published: September 2012

Prepared by OAK RIDGE NATIONAL LABORATORY

Oak Ridge, Tennessee 37831-6283

managed by

UT-BATTELLE, LLC

for the

U.S. DEPARTMENT OF ENERGY

under contract DE-AC05-00OR22725 



\section{CONTENTS}

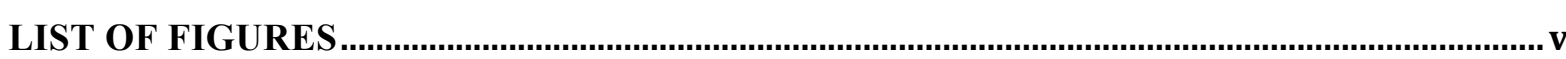

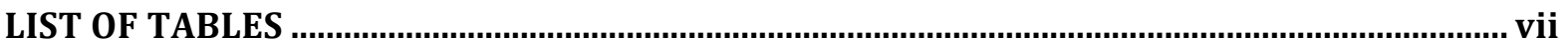

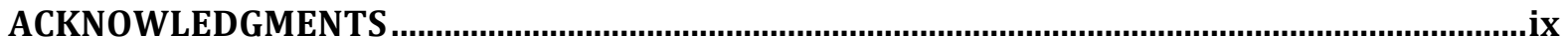

EXECUTIVE SUMMARY

1. INTRODUCTION

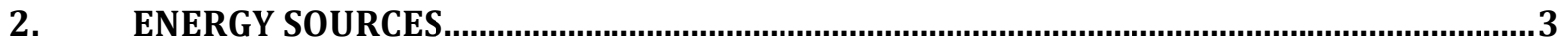

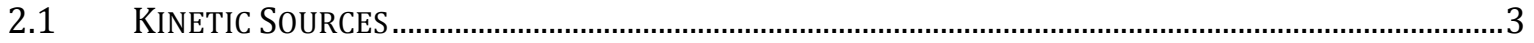

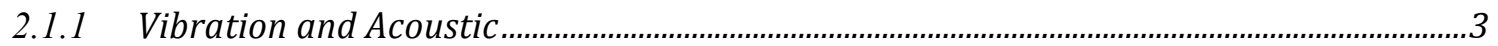

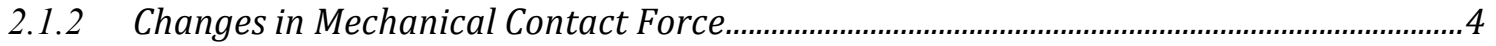

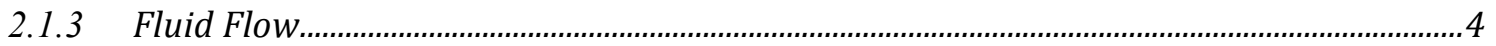

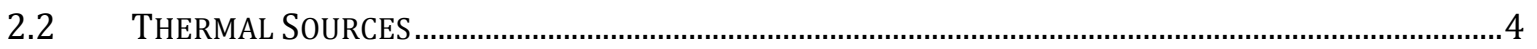

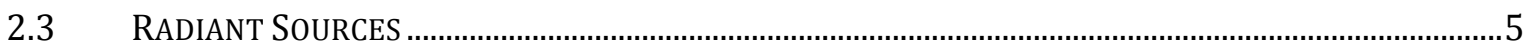

2.3.1 Light

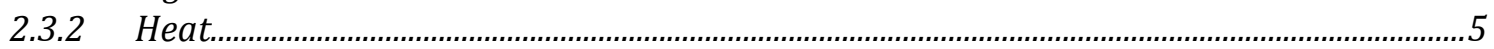

2.3.3 Radio-Frequency (RF) Radiation ...........................................................................................

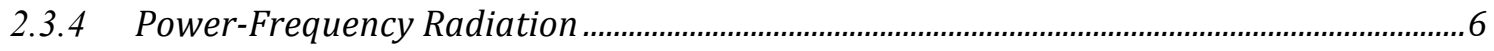

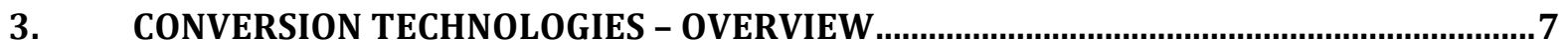

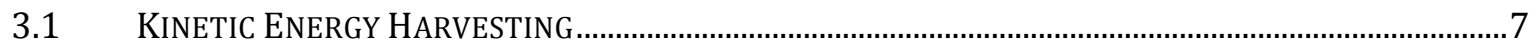

3.1.1 Vibration and Acoustic Energy ...................................................................................................

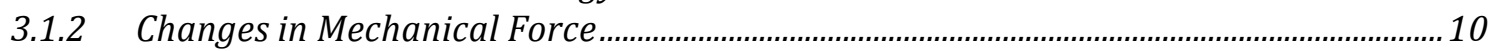

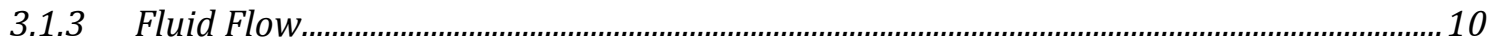

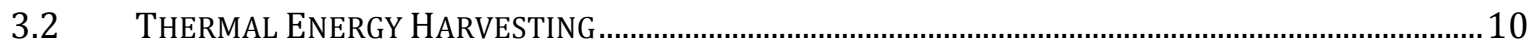

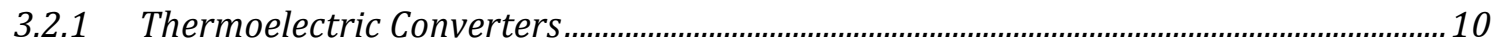

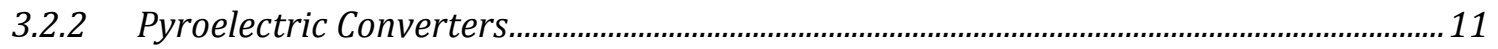

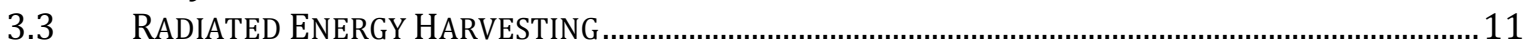

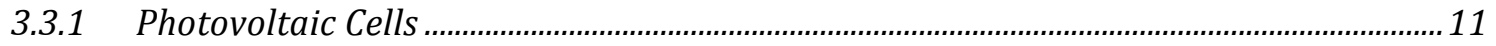

3.3.2 RF Collectors .............................................................................................................................11

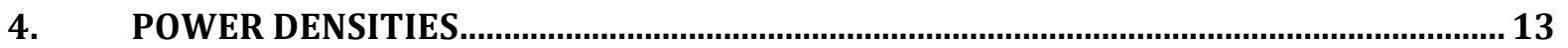

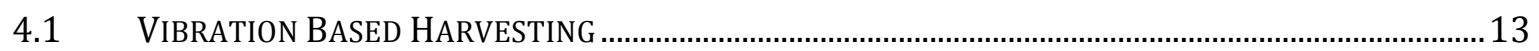

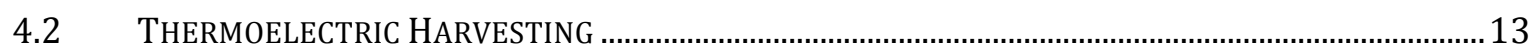

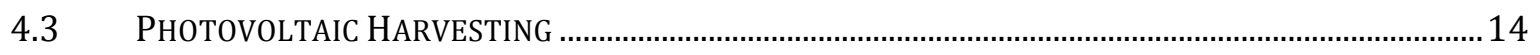

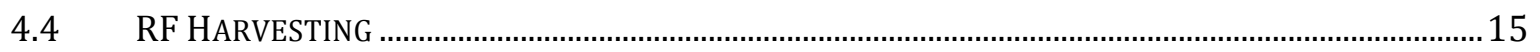

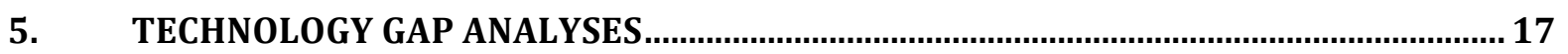

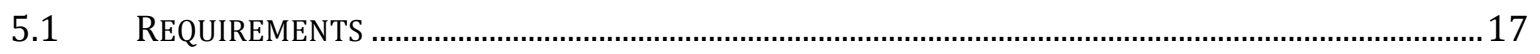

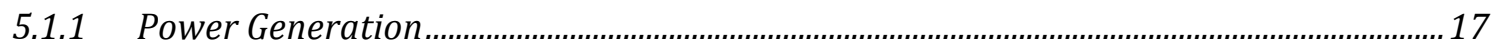

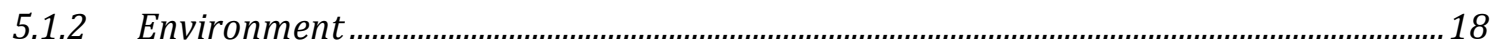

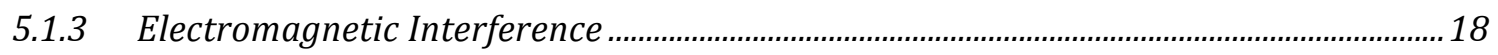

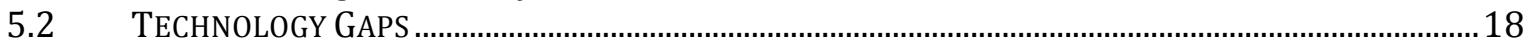

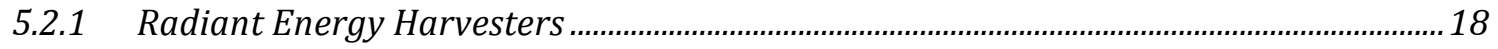

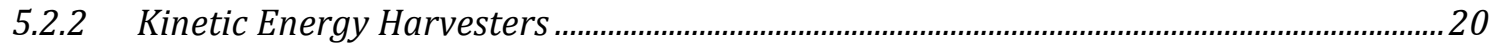

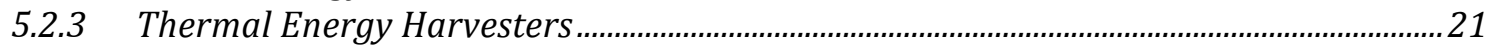

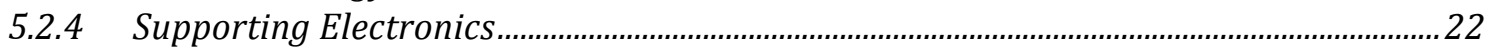




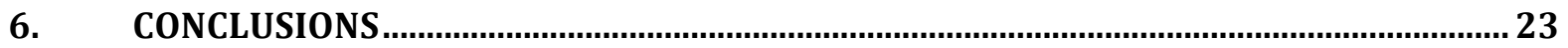

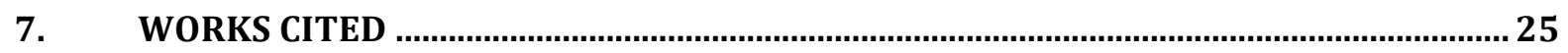

8. APPENDIX A. ENERGY HARVESTING TECHNOLOGIES BACKGROUND...................... 29

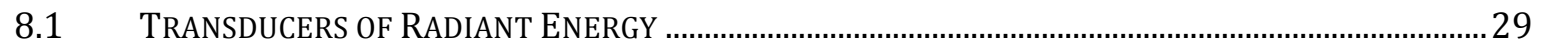

8.1.1 Natural and Artificial Visible Light .............................................................................29

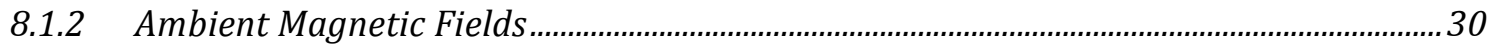

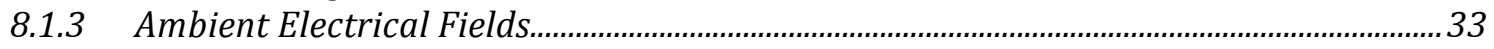

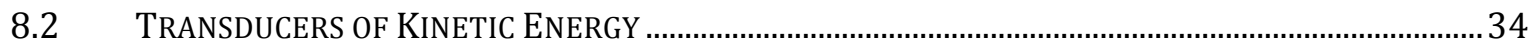

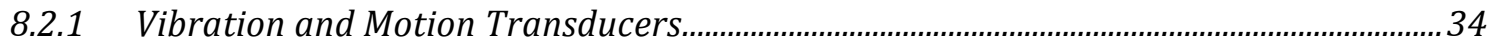

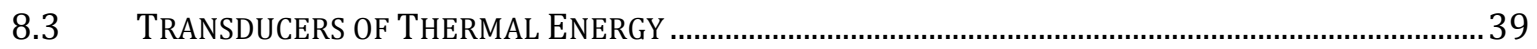

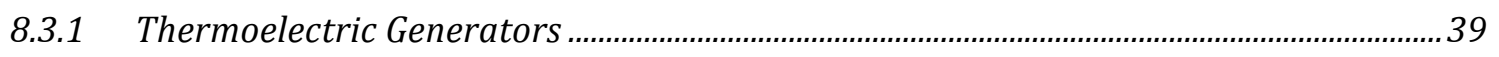

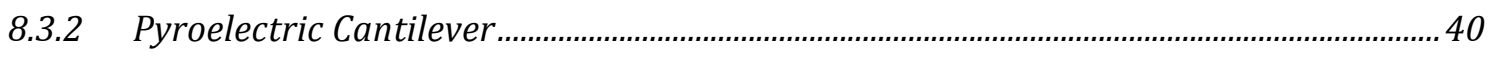




\section{LIST OF FIGURES}

Figure

Page

1 Elements of a self-powered wireless sensor node ............................................................... 2

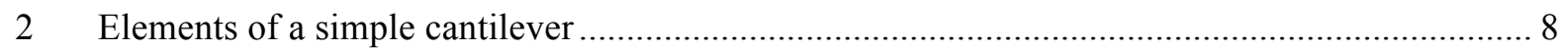

3 Estimated volume requirement for a vibration harvester based on acceleration ....................... 13

4 Estimated area requirement for a $20 \mathrm{~mW}$ TEG as a function of temperature differential........... 14

5 Collector area required for generating $20 \mathrm{~mW}$ using high-efficiency silicon solar cell.............. 15

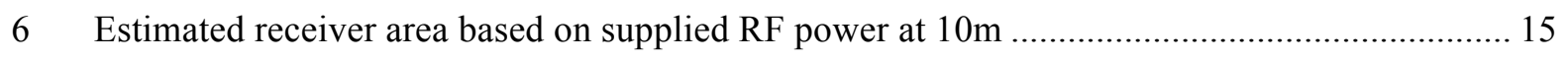

$7 \quad$ Semiconductor junction and the typical layer design for a PV cell ........................................... 29

8 A resonant-loop antenna tuned for short-wave reception ....................................................... 32

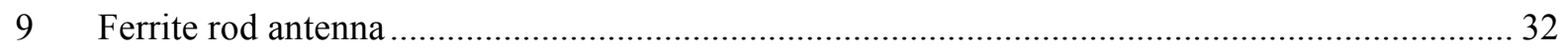

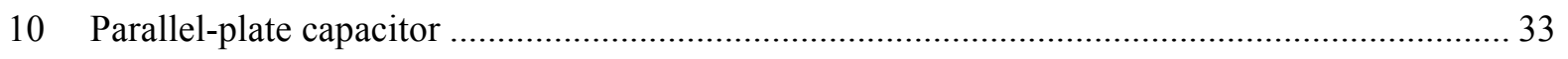

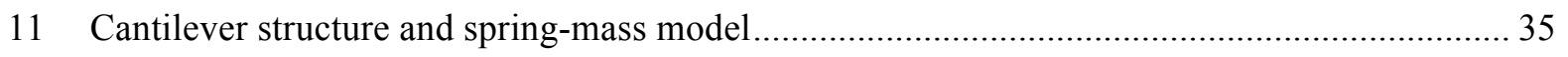

12 An example of an electrostatic vibration harvester: the electrostatic comb transducer.............. 36

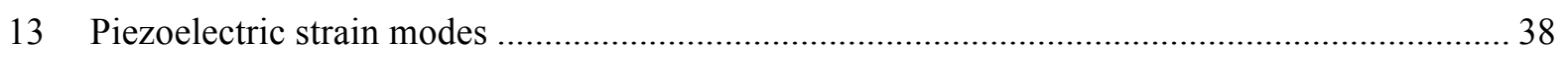

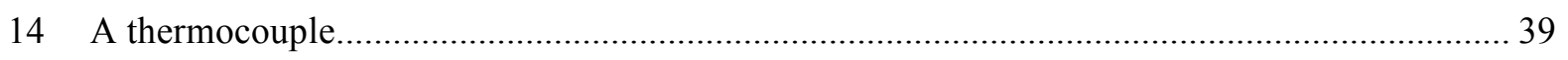

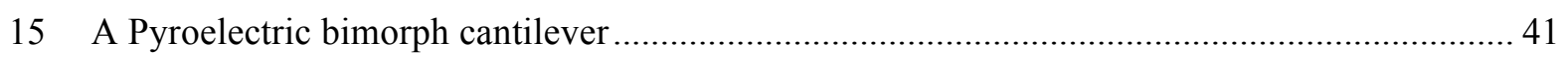





\section{LIST OF TABLES}

Table

Page

1 Examples of systems producing temperature differentials .................................................... 5

2 Power density estimates based on harvester dominant dimensions ........................................... 13

3 Power budget for a self-powered wireless sensor node .......................................................... 17

4 Ambient environment for normal and accident scenarios .................................................... 18

$5 \quad$ Integrated gamma dose for 6 months following loss-of-containment accident.......................... 18

6 Implementation gaps for power harvesting technologies in nuclear plant environment. ............ 24 



\section{ACKNOWLEDGMENTS}

This research was sponsored by the U.S. Department of Energy, Office of Nuclear Energy, for the Nuclear Energy Enabling Technologies effort. 



\section{EXECUTIVE SUMMARY}

Today's nuclear power plant (NPP) instrumentation uses current loops and voltage-based communications that are sometimes compromised by radio frequency interference (RFI), also called electromagnetic interference (EMI). Copper-based communications technology also relies on insulation that could degrade after decades of exposure to power plant environments and can be flammable. Wireless technologies offer the potential for greater expansion in instrumentation in a plant that could augment human performance, provide additional data on plant equipment and component status, and facilitate online assessment of the material condition of plants.

While wireless communications technologies applied to sensor networks facilitate the removal of one set of wires (i.e., communications wires), power is typically delivered over another set of wires. Without addressing the delivery of power to sensors, the full cost savings associated with the full removal of instrumentation wiring at a NPP is not realized. Development of methods to couple lowdrift, high-accuracy, low-power transducers with ambient power harvesting to produce a transducer that is capable of being installed during construction of the plant and operating reliably for many years and possibly until the plant is decommissioned is needed.

By using modern communications technologies and power harvesting techniques, cable runs could be significantly reduced by minimizing the need for many of the power cables to various sensors. Power harvesting would benefit all new reactor designs and fuel cycle facilities (e.g., enrichment facilities, mixed oxide fuel fabrication facilities, and used fuel deposition facilities) by helping to reduce maintenance and operating costs associated with installing wiring for replacement or temporary diagnostic sensors. Self-contained wireless sensor technology will also allow for larger numbers of sensors to be deployed cost-effectively, which will increase the redundancy, security, and safety of modern reactors. The main drawback to the current methods of harvesting energy is the low power levels that can be generated. These low power levels require electronics that have low energy dissipation and efficient data transmission protocols.

By combining wireless communications technologies with power harvesting techniques, development of truly wireless sensor nodes (WSNs) becomes a possibility. When wireless communications technologies and power harvesting techniques are ready for the nuclear reactor environment, the benefits will extend far beyond a reduction in cable installation and maintenance cost. Self-powered WSNs will provide a cost-effective way to add new or redundant measurements to existing plant instrumentation systems. Because nodes scavenging certain types of energy could continue to operate during extended station blackouts (SBOs) and during periods when operation of the plant's internal power distribution system has been disrupted, measurements identified as critical to accident management should be among the first targeted. The availability of this data would be invaluable not only to operators trying to manage an accident situation but to teams responsible for post-incident analyses as well. Self-powered WSNs and the networks that tie them together will provide an opportunity to make substantial improvements in the reliability and safety of modern NPPs.

The intent of this report is to examine power harvesting methods utilizing kinetic, thermal, and radiant sources. Technologies that harvest these energies are characterized by the power density achievable, physical reliability in harsh environments, and feasibility of packing with various sensors. Additionally this report assesses how well these various technologies, at their current maturity levels, meet the requirements of a sensor network in a NPP.

Appendix A summarizes the physical principles of various energy harvesting technologies. 



\section{INTRODUCTION}

Instruments in nuclear power plants (NPPs) and many industrial environments typically are served by at least two sets of wires; one set carries data and control signals and one set provides instrument power. Wireless communication devices are beginning to appear in a limited number of non-safetyrelated NPP applications [1] [2], and wireless sensor networks have proven to be less expensive, more flexible, and more reliable in industrial settings than their wired counterparts [3].

Robust digital instrumentation communication techniques and architectures are essential to address the potential for greater expansion in instrumentation in a plant that could augment human performance, provide additional data on plant equipment and component status, and facilitate online assessment of material condition of NPPs. To develop wireless alternatives to costly hardwiredcabling for real-time, online monitoring, demonstration of a high-reliability, secure wireless communications system for continuous data transmission is necessary.

In many industries, wireless mesh networks are beginning to replace conventional point-to-point wiring. Unfortunately, these existing wireless mesh networks do not have the extreme reliability required for NPP safety and control data, so additional research and development (R\&D) is necessary. To develop wireless alternatives to costly hardwired cabling for real-time, online monitoring, demonstration of a high-reliability, secure wireless communication system for continuous data transmission is necessary. This is especially true if wireless communications are used for transmission of measurement and control data as part of the plant control systems.

The use of wireless communications eliminates one set of wires. Unless power also can be delivered "wirelessly," the expense of installing and maintaining the power leads is still a burden. Recent advances in technologies for harvesting energy, especially waste energy, from the ambient environment are bringing the opportunity to implement truly wireless sensor nodes (WSNs) closer to reality.

Fortunately, NPP facilities are replete with environmental energy sources having potential to power wireless sensor nodes, including the following:

- Electromagnetic fields from nearby power busses and plant equipment

- Room lighting

- Hot piping and components

- Equipment vibration and motion

- Ventilation air flow

When power harvesting technology is ready for the nuclear reactor environment, the benefits will extend far beyond a reduction in cable installation and maintenance cost. Self-powered WSNs will provide a cost-effective way to add new or redundant measurements to existing plant instrumentation systems. Because nodes scavenging certain types of energy could continue to operate during extended station blackouts (SBOs) and during periods when operation of the plant's internal power distribution system has been disrupted, measurements identified as critical to accident management [4] would be among the first targeted. The availability of this data would be invaluable not only to operators trying to manage an accident situation but to teams responsible for post-incident analyses as well. Self-powered WSNs and the networks that tie them together will provide an opportunity to make substantial improvements in the reliability and safety of modern commercial reactors. 
The shortcomings of harvesting technologies currently available or under development are addressed later in this report (Section 5, Technology Gap analysEs) where we show that a primary issue for most approaches is generation capacity. Matching a compact and efficient energy-conversion device with an adequate energy source will be a significant challenge, as will minimizing energy consumption by other circuitry in the WSN (Figure 1).

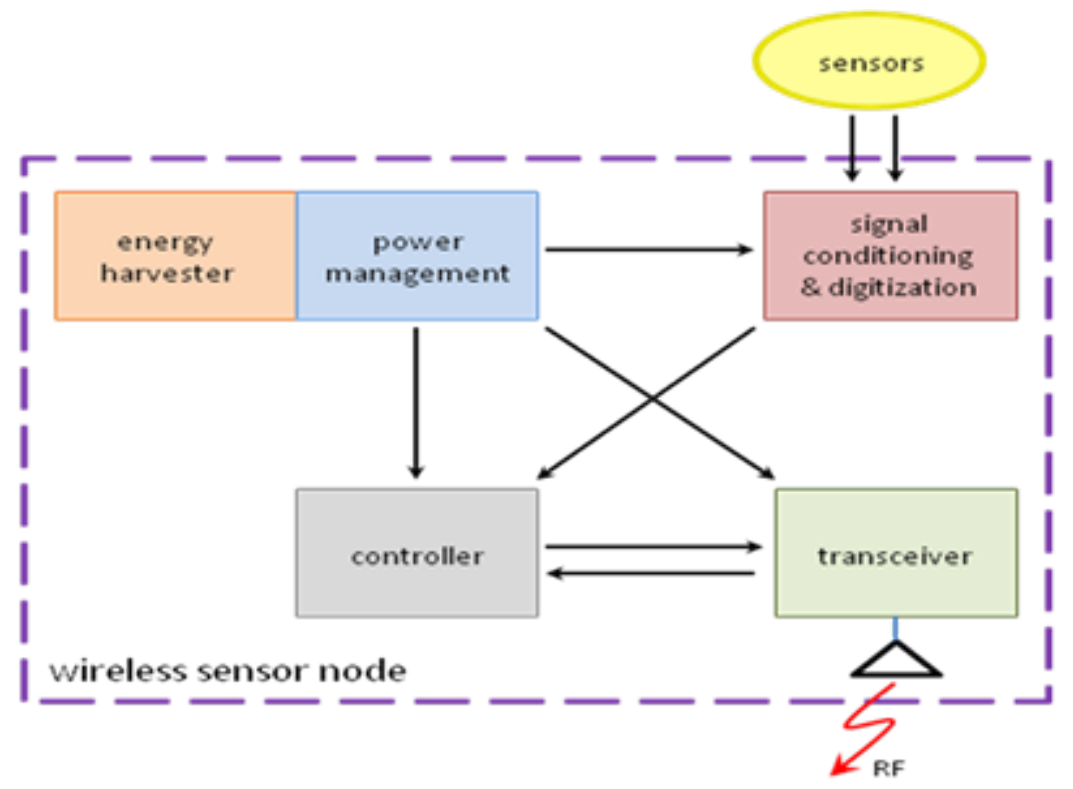

Figure 1. Elements of a self-powered wireless sensor node.

The demand for smaller packages and longer battery life in consumer electronics has driven the development of ultra-low power circuitry for the last decade, and self-powered WSN technology will benefit from these advances. Future program tasks will focus on the other component of reduced power consumption-low-power, low-data-rate wireless network architectures that can support secure and reliable communications. 


\section{ENERGY SOURCES}

In order for a network of sensor nodes to continue to function during prolonged SBOs, energy from sources that are likely to persist throughout the outage must be exploited. In this section, we list and briefly consider sources found in a NPP environment. We have organized them into three categories:

1. Kinetic - Energy that comes from motion or force

2. Thermal - Energy that comes from spatial temperature gradients or temporal temperature fluctuations

3. Radiated - Electromagnetic energy (including light) that is "broadcast" through space

We will focus on energy gathered from the ambient environment as opposed to energy intentionally introduced for the purpose of power generation. Details of harvesting technologies that can capitalize on these sources are delayed until the following section.

Energy harvesting sources and technologies have been the subject of intense research for the last decade. A useful overview is provided in [5], which includes an extensive bibliography.

\subsection{KINETIC SOURCES}

Human bodies, vehicles, bodies of water, machines, seismic activity, weather, and a multitude of other sources create motion and changing forces that provide opportunities for energy harvesting. Some sources are continuous, some are periodic, and some are intermittent. Some provide energy impulses, some provide energy in narrow frequency bands, and some are more random (wide spectrum) in nature. Motions and forces can be linear or rotational or a combination of the two. Each presents its own challenges and opportunities.

\subsubsection{Vibration and Acoustic}

Changes in displacement of structural surfaces or air molecules require energy. Accelerometers and microphones are familiar devices, which capture tiny amounts of energy from these motions and convert them to electrical signals. The energy levels of their signals are so small that they require amplification before they can be useful. Even when exposed to noise and vibration levels high enough to be uncomfortable for humans, these devices generate power levels in the sub-microwatt range.

Vibration and acoustic energy can be characterized by amplitude and by frequency content. While accelerometers and microphones operate over wide frequency ranges, individual energy harvesting transducers operate over narrower ranges that must be matched to the characteristics of the energy source.

Except for machinery that operates continuously, sources of noise and vibration tend not to be stable. However, source behavior often can be predicted.

Current topics of research in vibrational energy harvesting include the following:

- Creating very small transducers and achieving high packing densities

- Matching electrical and mechanical impedances for efficient energy transfer 
- Matching transducers' effective frequency ranges to the characteristic vibration frequency spectra of the target sources

Closely related to structural vibration is low-frequency, relatively large mechanical displacement, which often occurs in an aperiodic manner. The motion of a buoy on an ocean's surface serves as an example.

Development efforts over the last decade are paying off as devices become available to provide useable amounts of electrical energy derived from mechanical vibrations. Systems for harvesting energy from traffic-induced bridge vibrations, for example, have been demonstrated to power modest data acquisition devices for bridge health monitoring purposes [6].

\subsubsection{Changes in Mechanical Contact Force}

Progress has been made in exploiting this type of energy as well, and has moved from novelty or limited-purpose applications (e.g., flashing LEDs on children's shoes or spark generators for igniting propane gas) to useful semi-continuous energy-producing systems. As an example, illumination for high-traffic pedestrian walkways at last summer's Olympic Games in London were powered by converting energy lost in the inelastic impacts of feet on floor tiles into electricity [7].

Sources of modulated force tend to be discontinuous or even sporadic. Many vary depending on other activities going on in the nearby environment. Some types vary predictably (e.g., gravitational), while other types (e.g., seismic) can be relatively difficult to forecast very far into the future.

Increases and decreases in force can create flow of electrical charge directly in materials that respond to stress, or they can cause deformation (bending or flexing) of material capable of generating charge when strained.

Mechanical force can serve as an intermediate step in converting energy from one form to another. Changes in temperature or magnetic field strength, for example, can create force changes useful in electricity production.

\subsubsection{Fluid Flow}

Flowing fluids are abundant in both natural and man-made environments. Ship sails and water wheels were "harvesting" energy from naturally created fluid flow millennia ago. Electricity was first generated using hydropower in the United States in 1880 [8]. Modern-day research is focusing on ways to harvest energy using devices having no moving parts.

In a NPP environment, flowing fluids are serving a purpose (e.g., reactor cooling or room ventilation) and energy scavenged from these flows would not be waste energy.

\subsection{THERMAL SOURCES}

Heat sources are abundant in many environments. In many cases, the heat is an unneeded (and often undesired) by-product of the generation or utilization of other types of energy. Thermal energy is useful for harvesting if spatial temperature gradients exist (by using thermoelectric materials) or temperatures change with time (by using pyroelectric materials). 
Table 1 lists examples of frequently encountered sources of temperature gradients produced by human activity. Differentials (relative to ambient temperatures) produced by waste heat are common.

Table 1. Examples of systems producing temperature differentials

\begin{tabular}{|c|c|c|}
\hline Location & Source & Differential $\left({ }^{\circ} \mathrm{C}\right)$ \\
\hline Factories & $\begin{array}{l}\text { exhaust systems } \\
\text { boilers } \\
\text { condensers } \\
\text { motors }\end{array}$ & $10-80$ \\
\hline Vehicles & $\begin{array}{l}\text { engine } \\
\text { exhaust systems }\end{array}$ & $\begin{array}{c}60 \\
>100\end{array}$ \\
\hline Airplanes & cabin vs. external & $10-50$ \\
\hline
\end{tabular}

Because they transfer thermal energy from a warmer surface to a cooler surface, energy harvesting devices that exploit temperature gradients can provide a useful cooling function while reducing thermal pollution and generating electricity.

Most human-induced and naturally occurring temporal temperature changes are so slow that their thermal cycle times (seconds, minutes, hours, days, or even longer) are too long to be useful for energy harvesting [9]. Temperature changes that are large enough and fast enough to generate substantial amounts of electricity must be created artificially.

\subsection{RADIANT SOURCES}

Our environment is literally flooded with radiated electromagnetic energy from natural and manmade sources. The sun is a major source - solar insolation exceeds $1 \mathrm{~kW} / \mathrm{m}^{2}$ at prime times in prime locations on the earth's surface. Intensities of other ambient sources pale in comparison unless locations very close to power transmission equipment or radio transmitters or intense artificial light sources are considered.

\subsubsection{Light}

Sunlight closely approaches the ideal "white light" source with relatively uniform energy levels at wavelengths from infrared to ultraviolet. Artificial light from halogen incandescent bulbs can produce a similar spectrum. Light from most other artificial sources is weighted more heavily at one end of the spectrum or is concentrated at one or more narrow wavelength ranges. Office-level lighting is two orders of magnitude lower in intensity than bright sunlight.

Of course, the intensity of sunshine varies according to season, time of day, and weather conditions. Ambient artificial light is often cyclical, also, and relies on the application of electrical energy or the provision of fuel.

\subsubsection{Heat}

Heat radiates through the environment in a manner similar to light, but to be useful for harvesting, it must be absorbed by a material. 


\subsubsection{Radio-Frequency (RF) Radiation}

Any given volume of space in our environment is exposed to energy from numerous artificial and natural RF sources. Unfortunately for power harvesting purposes, sources of ambient RF fields are usually distant and not coherent in phase. Even when using very large collectors (antennas), the net recoverable energy is exceedingly small.

Radiating RF energy is always comprised of both magnetic fields and electrical fields. Decisions regarding which type of field to capture depend on relative source voltage and current amplitudes, on distance between source and receiver, on signal frequency, and on a multitude of other factors.

\subsubsection{Power-Frequency Radiation}

Power transmission lines, motors, generators, and transformers radiate electrical and magnetic fields at low frequency $-60 \mathrm{~Hz}$ in the United States. Field strengths drop off very rapidly as the distance between the current-carrying elements and the observer increase, however. The familiar high-voltage power transmission line serves as an example. Because the sum of the currents in the three power conductors is very close to zero (as do the three voltages), net field strength (electric or magnetic) rapidly approaches zero at distances from the line that are greater than the separation between the power conductors. 


\section{CONVERSION TECHNOLOGIES - OVERVIEW}

For each of the families of energy sources listed in the previous section, we briefly examine the types of technologies that have are being used to convert energy into electricity. More detail on the physical principles behind each type of harvester is presented in Appendix A.

\subsection{KINETIC ENERGY HARVESTING}

Three distinct methods exist for harnessing waste vibrational energy. These are piezoelectric generation, electromagnetic generation, and electrostatic generation. The first relies on the piezoelectric effect; certain materials will generate an electrical current when placed under mechanical strain. This method lends itself to generating high voltages, but low currents. Piezoelectric generators have been demonstrated in Microelectromechanical Systems (MEMS) devices, and performance does not suffer significantly on the microscale. Clearly, the piezoelectric properties of the chosen material directly influence the performance of the generator. However, the mechanical properties of the piezoelectric materials are also nontrivial for this generation method, as the piezoelectric elements must be directly stressed.

The second method relies on traditional induction; a magnet is moved relative to a coil of wire, producing a current. Electromagnetic generation lends itself to relatively high-current, low-voltage output. This method does not scale well; microscale implementations perform poorly in comparison to their larger counterparts. The effectiveness of electromagnetic generators heavily relies on the properties of both the magnet and the coil that are used.

The final method, electrostatic generation, relies on a variable capacitor ("varactor"). Mechanical motion can be used to change the distance between, or degree of overlap of, the plates of a capacitor. This method requires a preexisting voltage source, as an uncharged capacitor will be useless for power generation in this way. Electrostatic generation lends itself to high-voltage, low-current output. This method scales well; MEMS devices have been created which utilize it. However, electrostatic generation methods are immature in comparison with piezoelectric and electromagnetic methods.

A fourth method for harvesting mechanical energy is generation based on the triboelectric effect. This describes the tendency for some materials to become electrically charged when brought into contact with one another by pressing or rubbing. A common example of this effect is the static electricity encountered in everyday activities. Researchers are beginning to cultivate triboelectricity as a potential source of energy for harvesting [10].

Harvesting kinetic energy inevitably involves mechanical systems that can be relatively complex. The presence of moving parts severely limits the maximum useful life span of these harvesters. In practical application, the sources of kinetic energy are most often man-made, such as factory equipment or vehicles. This means that a loss of power to the source is possible, and would cause the harvester to cease output.

\subsubsection{Vibration and Acoustic Energy}

Waste vibrational energy can be harnessed using any of the three methods described above. Vibration-based harvesters generally utilize a cantilever with a mass attached to the end. When attached to a vibrating structure, the vibration will cause the free end of the cantilever to oscillate. This can be used to stress a piezoelectric element, move a magnet relative to a coil, or alter the distance between the plates of a capacitor, generating an AC current. 
Pure cantilever-based harvesters can only operate effectively over a very small range of vibration frequencies. This is because such harvesters must operate at their resonant frequency, or their power output is negligible. As a result, individual harvesters must be "in tune" with their target vibration sources or they will not be effective. Two distinct methods have been devised to increase the range of frequencies for which vibration-based generators are effective. The first is a brute force method. Harvesters are built with multiple cantilever arms, each of which is designed to operate at a different resonant frequency. This causes the generator to consume far more space, reducing power density. The second is to design more complex cantilever systems that can be tuned after production, or are even capable of a limited degree of self-tuning. Such systems utilize adjustment mechanisms to directly alter the mechanical properties of the system. For example, the effective stiffness of the cantilever can be altered, or the location of the mass on the cantilever can be changed. Such selftuning mechanisms can operate continuously, or make occasional adjustments and remain inactive at other times. These tuning mechanisms consume energy, and the tuning device can negatively affect the effectiveness of the device if poorly designed.

In addition to improving the effective frequency range of harvesting devices, modifications have been introduced and proposed to increase the overall effectiveness of these devices. In particular, piezoelectric harvesters receive a relatively large degree of experimental attention. For example, alterations to the shape of the cantilever arm in order to produce a more uniform strain on the piezoelectric elements have produced measurable increases in output. Cantilevers with a trapezoidshaped profile, rather than the traditional rectangular profile, show the greatest gains [11].

The most promising technologies for converting vibration into electrical energy involve

- converting mechanical displacement into stress or, more often, strain and using piezoelectric materials to create electrical charge on capacitor plates,

- using the mechanical displacement to modulate the separation between a magnet and a pickup coil and capturing the magnetically induced current from the coil, or

- using the mechanical displacement to modulate the distance between two capacitor plates, capturing the electrostatically induced current from the capacitor.

Nearly all vibration transducers employ some type of mass-on-spring resonance to boost output. In the three approaches listed above, microcantilevers (Figure 2) are being used to enhance the generation process. These cantilevers exhibit sharp mechanical resonances, so they are effective only over narrow frequency ranges and must be matched to the frequency characteristics of the vibration sources.

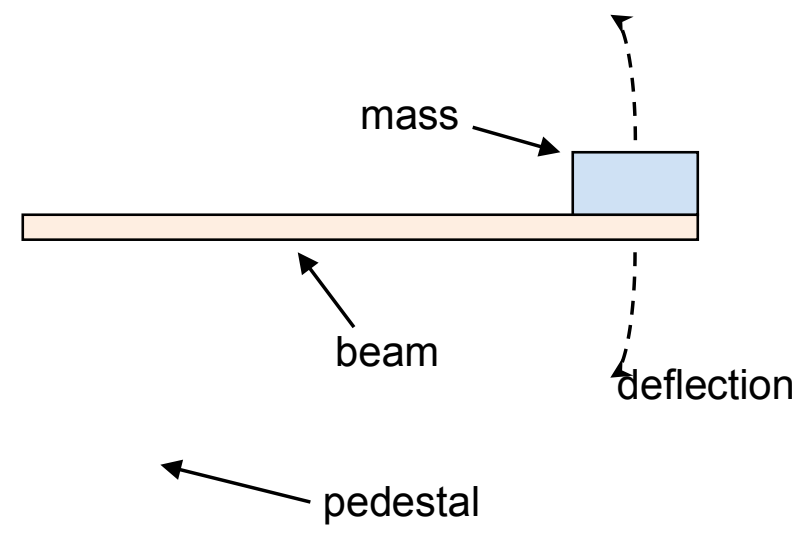

Figure 2. Elements of a simple cantilever. 
To cover wider frequency ranges, multiple sets of cantilevers, each tuned to a distinct frequency band, can be connected together so that one of the sets is operating near resonance at any given time. In another approach, mechanical characteristics of cantilevers can be actively tuned to match the source's frequency content by varying the stiffness of the cantilever or introducing an offset displacement [12]. At present, tuning ranges are relatively limited, especially in self-tuning devices, and tuning mechanisms consume a portion of the energy produced.

\section{Piezoelectric transducers}

Piezoelectric transducers convert motion in the surface of the vibration source into strain in a microcantilever constructed from a piezoelectric material. Metallic electrodes deposited on opposite sides of the cantilever beam form capacitor plates and collect generated electric charge.

Output from a piezoelectric generator is usually at a relatively high AC voltage level (but low current level) and exhibits a high output impedance. The technology lends itself well to fabrication using MEMS techniques, yielding high densities of generators. Challenges include the development of cantilever beam materials and shapes having favorable piezoelectric characteristics and mechanical properties. The shape of the cantilever beam can be tailored to optimize locations where strain is created [13].

\section{Magnetic induction transducers}

In a magnetic induction transducer, magnetic flux through a coil of wire is varied by changing the displacement and/or orientation of a permanent magnet relative to the coil. In low-frequency devices, relatively massive magnets are mounted on springs (usually metal or plastic) so that impulses or vibrations cause the magnet to oscillate around a central position, creating an AC current in the coil. At higher frequencies, the spring is replaced with a cantilever beam and the magnet serves as the tip mass.

At microscale, attaching suitable magnets to cantilevers is difficult, so generator densities tend to be lower than for piezoelectric devices. Outputs feature low voltages but high currents and low output impedances.

\section{Electrostatic induction transducers}

By varying the relative displacement between two electrodes of a capacitor, current can be made to flow through an external circuit. Fixed-charge (electret) or fixed-voltage circuits are used. In some approaches, part of the energy generated is required for biasing the capacitor. Complex electrode shapes are used to maximize their surface areas and maximize electrostatic coupling between the plates.

As with piezoelectric transducers, which are also capacitive in nature, electrostatic converters feature relative hig voltages and output impedances. The technology adapts well to MEMS fabrication and, although relatively immature, is currently a subject of intense research.

\section{Acoustic energy transducers}

Very little work is being performed on harnessing acoustic energy in ordinary environments because of the low energy density of all but dangerously loud sound fields. Some devices have been demonstrated that produce electrical power at the microwatt level from sound levels tolerable by humans, but obtaining milliwatts requires intense fields like those encountered at jet engine test stands [14]. 


\subsubsection{Changes in Mechanical Force}

Piezoelectric materials respond to stress as well as strain, so output current can be captured even when there is no significant deformation of the material. Impulse forces produce energy pulses. Slowly varying forces produce correspondingly low output power levels.

Cantilevers and other mass-spring systems can convert impulse forces into oscillating forces, allowing the technologies for vibration sensors discussed above to be employed.

Energy from changing forces can, in some cases, be harvested using the triboelectric effect. Triboelectric materials produce static electricity when pressed or rubbed against other materials. Energy can be harvested from these charged capacitances. The voltages produced can be very high, tens of $\mathrm{kV}$ and higher, which requires fundamentally different circuitry for energy capture.

\subsubsection{Fluid Flow}

Windmills and water wheels are two familiar devices for tapping into the energy of environmentally driven fluid flow. Fluid-powered electrical generators using rotating components are being developed on relatively small scales, but much of current research on smaller scale generators focuses on devices with no moving parts or components that deflect only slightly. These devices exploit (and, in some cases, introduce) varying forces from turbulence and vortices in the passing fluid.

If ions are entrained in the flowing fluid, a magnetic field and the force behind the flow can be used to separate positive and negative ions and direct them to electrodes in contact with the fluid, creating electrical current - a technology called magnetohydrodynamics. If ions are plentiful and moving at high speeds, as in a jet engine exhaust stream, then significant amounts of energy can be generated.

\subsection{THERMAL ENERGY HARVESTING}

The majority of thermal harvesting devices feature no moving parts and, if they are not subjected to severe environmental stresses, relatively long effective life spans. The maximum achievable efficiency for any thermodynamic device is limited to its theoretical Carnot efficiency [15], which is determined by the difference in temperatures of the heat source and the heat sink. Greater temperature differentials yield greater theoretical efficiencies.

\subsubsection{Thermoelectric Converters}

Thermoelectric generators (TEGs) utilize the Seebeck effect to extract electrical energy from a temperature difference between two surfaces. Semiconductor thermocouples, consisting of one p-type material and one n-type material, are usually used in thermoelectric harvesters. Bismuth telluride $\left(\mathrm{Bi}_{2} \mathrm{Te}_{3}\right)$ is the most often used material, but recent research has produced significant efficiency increase with the use of silicon nanowires [16] [17].

Details of TEG design involve matching thermal impedances and electrical impedances to maximize electrical power generation. In many designs, a performance-limiting factor is the ability of the device's heat sink to dump heat into the ambient environment. If this exchange happens too slowly, the cool side of the generator warms up and the hot-to-cool side temperature differential is decreased.

New materials such as graphite foam offer dramatic improvements in heat sink performance [18]. Ounce-for-ounce, graphite foam exhibits specific thermal conductivity up to seven times greater than 
copper and five times greater than the more commonly used aluminum alloys. This increased performance allows lightweight, reasonably sized heat sinks without forced-air convection.

\subsubsection{Pyroelectric Converters}

Pyroelectric materials are used to derive energy from cyclical changes in temperature. Different temperatures create different degrees of spontaneous polarization in the bulk of the material. When material temperature changes, the amount of charge collected by metal electrodes on opposite surfaces of the material changes also, producing an AC electrical current.

Some pyroelectric materials maintain their properties at very high temperatures, beyond $1200^{\circ} \mathrm{C}$, providing the potential to reach high Carnot efficiencies. Until recently, the limiting factor on generation capacity has been the ability to rapidly cycle temperature. A recent development provides the potential to cycle temperatures hundreds of times per second [19], allowing pyroelectic generation to compete very favorably with the more mature TEG technology.

\subsection{RADIATED ENERGY HARVESTING}

\subsubsection{Photovoltaic Cells}

Technology for converting visible light to electrical energy is dominated by photovoltaic generation. Compared to state-of-the-art solar cells in direct sunlight, all other approaches fall short in power density or cost-per-watt comparisons.

Solar cells are constructed so that photons can reach the junction between layers of p-type and n-type semiconductor materials. Each photon absorbed in the junction generates a carrier pair. Because of the rectifying action of a $\mathrm{p}-\mathrm{n}$ junction, negative carriers (electrons) migrate in one direction and positive charges (holes) move in the opposite direction.

The resulting electrical power has highly desirable characteristics - relatively high voltage, high current, and low output impedance. Cells can be configured in series and parallel combinations to provide convenient voltage and current capacities. Almost all available cells feature anti-reflective coatings, which allow more photons to reach the p-n junction, and improve output capacity.

Conversion efficiency is a strong function of illumination level. Cells exposed to bright sunlight have greater output than one in a typical indoor artificial lighting environment, not only because the light is so much brighter (by a factor of approximately 100) but also because they operate much more efficiently at that level - typically $2.5 \%$ for an office environment compared to $20 \%$ in direct sunlight [20]. For even more intense light gathered with the aid of solar collectors, efficiency can reach $40 \%$.

Silicon photocells dominate the market and ongoing research because of mature technology, an established manufacturing capability, reasonable cost, and good efficiency. Devices built using other materials are being developed and are on track to close the gap with silicon [21].

\subsubsection{RF Collectors}

Radiofrequency energy, or RF, is harvested via the utilization of either inductive coupling or capacitive coupling. These coupling techniques are used to tap into electromagnetic fields. The harvester takes the form of an antenna, and outputs an AC current. It has been demonstrated that ambient RF energy is limited in the extreme and is not present in sufficient quantity to power useful devices. As a result, an artificial supply is always necessary. This supply can come in the form of a 
transmitting tower for communications, or can come from a dedicated RF generator. No matter the source, the effectiveness of an RF harvester is directly tied to its distance from said source. The energy available to the device decreases drastically the farther it is from the source.

Even the field strength from a FM radio station transmitter a few blocks away is on the order of $100 \mathrm{mV} / \mathrm{m}$, which might result in a signal strength of $10 \mathrm{mV}$ at the output of a large FM antenna, corresponding to a $300 \mathrm{nW}$ power level. Because of the weak energy levels in ambient RF fields, even impractically large antennas lack the capability to collect enough energy for the $20 \mathrm{~mW}$ application. 


\section{POWER DENSITIES}

This section provides a brief summary of estimated power densities that can be harvested from the different energy sources (Table 2).

Table 2. Power density estimates based on harvester dominant dimensions [22], [23]

\begin{tabular}{|l|l|l|}
\hline & Energy Source & Power Density \\
\hline \multirow{2}{*}{ Vibration/Motion } & Human & $4 \mu \mathrm{W} / \mathrm{cm}^{2}$ \\
\cline { 2 - 3 } & Industry & $100 \mu \mathrm{W} / \mathrm{cm}^{2}$ \\
\hline \multirow{2}{*}{$\begin{array}{l}\text { Temperature } \\
\text { Differential }\end{array}$} & Human & $25 \mu \mathrm{W} / \mathrm{cm}^{2}$ \\
\cline { 2 - 3 } Radiant Light & Industry & $1-10 \mathrm{~mW} / \mathrm{cm}^{2}$ \\
\cline { 2 - 3 } Radiant RF & Indoor & $10 \mu \mathrm{W} / \mathrm{cm}^{2}$ \\
\hline & Gutdoor & $10 \mathrm{~mW} / \mathrm{cm}^{2}$ \\
\cline { 2 - 3 } & Wi-Fi & $0.1 \mu \mathrm{W} / \mathrm{cm}^{2}$ \\
\hline
\end{tabular}

Based on these figures and others found in the literature, we provide rough estimates of the size of a $20 \mathrm{~mW}$ harvester for each of the technologies considered below.

\subsection{VIBRATION-BASED HARVESTING}

Typical power densities for vibration-based harvesting fall near $100 \mu \mathrm{W} / \mathrm{cm}^{3}$ when excited by an acceleration amplitude of $1 \mathrm{~m} / \mathrm{s}^{2}$ [22]. Estimates of the required harvester volume as a function of vibration amplitude are shown in Figure 3. Estimated volume requirement for a vibration harvester based on acceleration

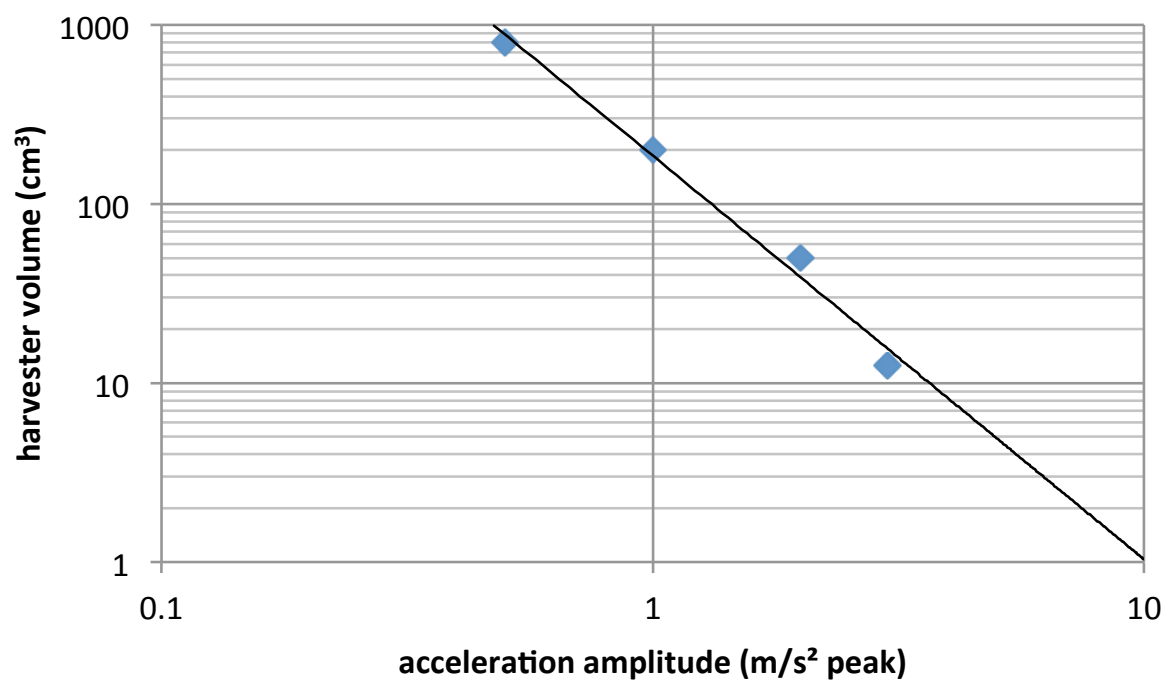

Figure 3. Estimated volume requirement for a vibration harvester based on acceleration.

\subsection{THERMOELECTRIC HARVESTING}

For a continuous temperature difference of $5^{\circ} \mathrm{C}$, typical power density is about $60 \mu \mathrm{W} / \mathrm{cm}^{2}$. Capacity increases approximately linearly with temperature differential. Figure 4 can be used to obtain an approximation of the size of the surface contact area required to obtain $20 \mathrm{~mW}$ from a standard TEG [24]. 


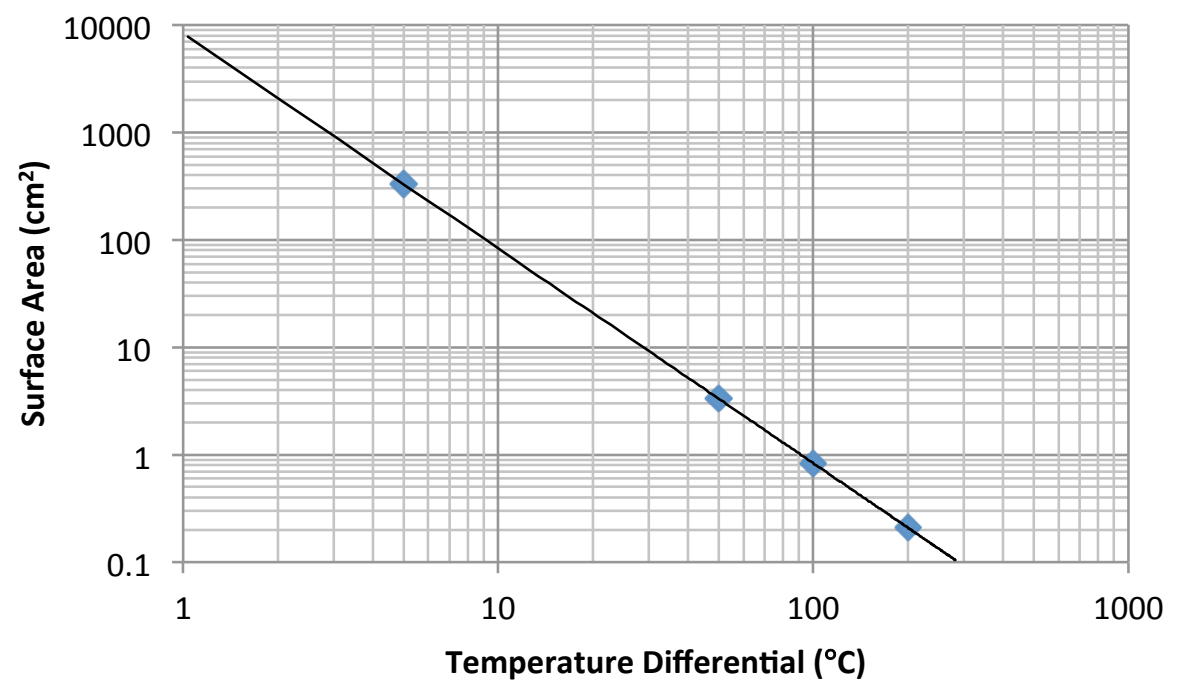

Figure 4. Estimated area requirement for a $20 \mathrm{~mW}$ TEG as a function of temperature differential.

This projection is based on models of traditional thermoelectric generators. New self-oscillating pyroelectric converters, which will be able to serve as direct replacements for TEGs, promise at least a $5 \times$ improvement in power density.

\subsection{PHOTOVOLTAIC HARVESTING}

In any outdoor situation, photovoltaic cells have a clear advantage over other methods, attaining power densities averaging $10 \mathrm{~mW} / \mathrm{cm}^{2}$ during daylight hours using readily available technology. However, power density in a well-lit indoor environment is comparable with other methods, as a typical cell will gather roughly $20 \mu \mathrm{W} / \mathrm{cm}^{2}$. The conversion efficiency of a photovoltaic cell is not constant, but increases with light intensity. As a result, cell capacity is not proportional to illumination level.

Figure 5 shows an approximation of how the size of a $20 \mathrm{~mW}$ photovoltaic array would vary according to illumination level. 


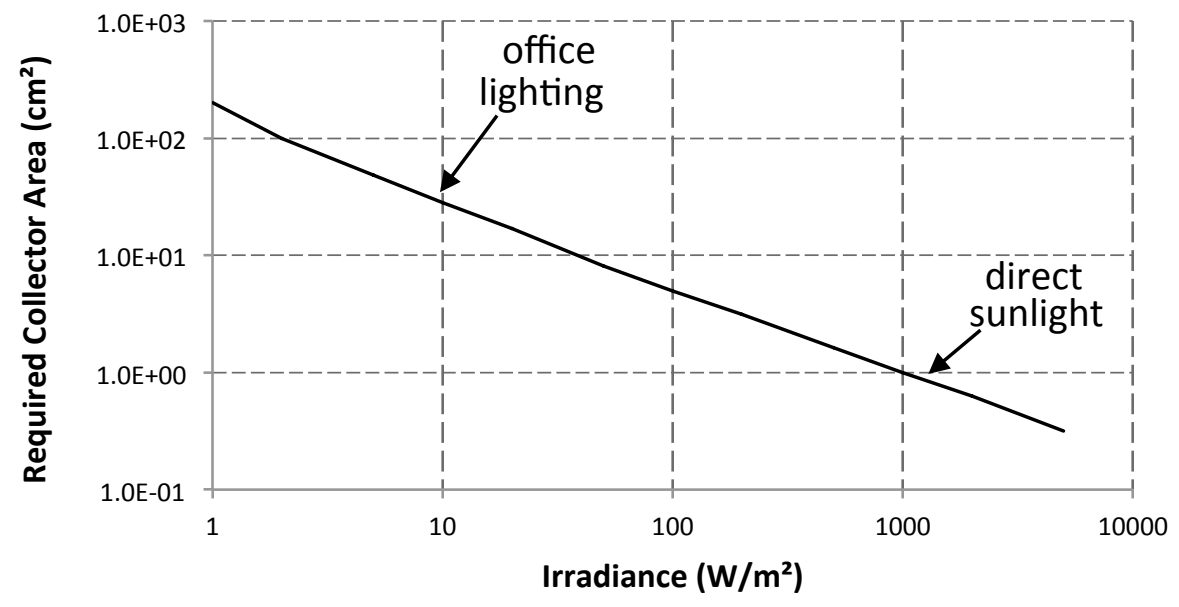

Figure 5. Collector area required for generating $20 \mathrm{~mW}$ using high-efficiency silicon solar cell.

\subsection{RF HARVESTING}

RF harvesting requires the presence of a dedicated source in the vicinity of the harvester. Ambient RF energy is far too weak to supply a meaningful amount of power (it can be measured in $\mathrm{nW}$ ); for this reason, an artificial supply is necessary. Distance from the source is the most potent factor in determining the effectiveness of RF harvesters. Harvesters at a range of $10 \mathrm{~m}$ from a $0.5 \mathrm{~W}$ source can attain up to $0.4 \mu \mathrm{W} / \mathrm{cm}^{2}$ of effective power density. The scale of the receiver given a certain radiated power at $10 \mathrm{~m}$ can be roughly determined, if the goal of $20 \mathrm{~mW}$ is maintained. This assumes an antenna efficiency of $20 \%$, as this is the estimated upper limit for microwatt-level devices [25].

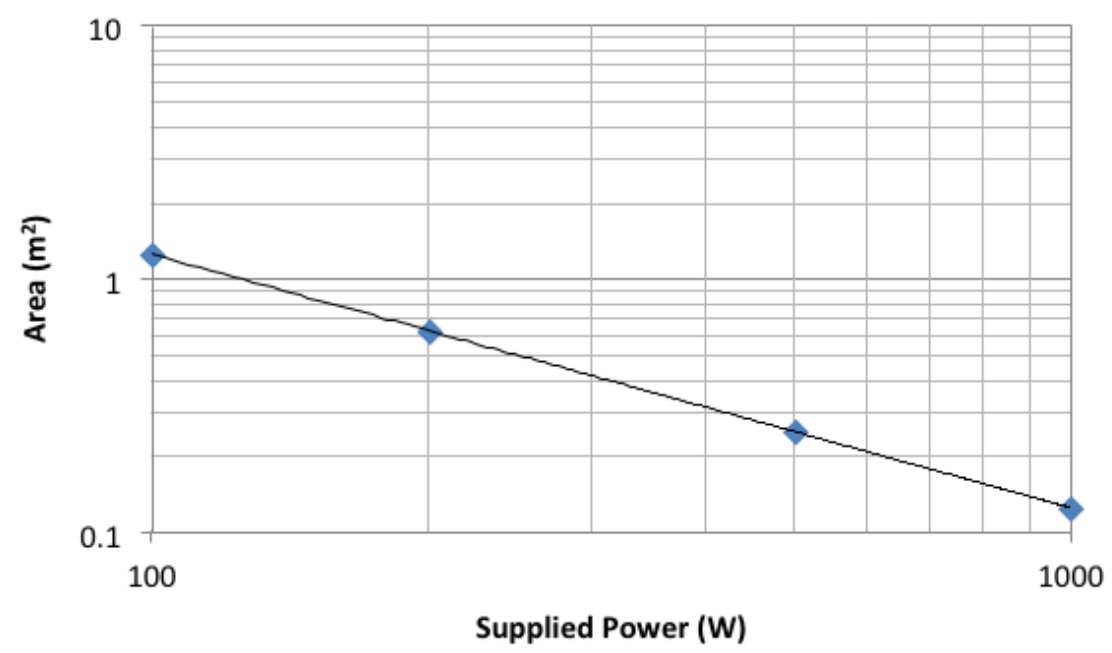

Figure 6. Estimated receiver area based on supplied RF power at $10 \mathrm{~m}$.

Ambient RF field strengths in any realistic environment are simply inadequate for obtaining power levels of this magnitude. 



\section{TECHNOLOGY GAP ANALYSES}

In addition to having adequate power generation density, a harvester must

- survive and function in its environment,

- rely on an energy source that is available whenever needed, and

- not interfere with plant operations.

In this report, we examine how well the various technologies, at their current maturity levels, can meet these requirements and identify shortcomings (technology "gaps") that would need to be addressed before they could be deployed in a NPP environment.

\subsection{REQUIREMENTS}

\subsubsection{Power Generation}

To arrive at a baseline power estimate for a hypothetical sensor node (Table 3), we chose to include signal conditioning and digitization electronics for four thermocouples, a small microprocessor, and a radio transceiver that consumes twice as much power during the transmit cycle as the most efficient available ZigBee [26] tranceivers. Other sensors will be examined during a later phase of the project. We assume one transmission of data from this node every 10 seconds as well as several relays of data from other nodes every second. We also assume that low-power, commercial off-the-shelf components are used and that power to the thermocouple cold-junction compensation (CJC) subcircuits can be turned off between measurements.

\section{Table 3. Power budget for a self-powered wireless sensor node}

\begin{tabular}{|c|c|}
\hline Transceiver, including encryption & $9 \mathrm{~mW}$ average \\
\hline Microcontroller & $200 \mu \mathrm{W}$ \\
\hline Four channels of CJC and amplification & $1 \mathrm{~mW}$ average \\
\hline Quad 12-bit analog-to-digital converter & $18 \mu \mathrm{W}$ \\
\hline Miscellaneous circuitry & $<3 \mathrm{~mW}$ \\
\hline $\begin{array}{l}\text { Power loss in } 85 \% \text { efficient power } \\
\text { conversion/management circuit }\end{array}$ & $2 \mathrm{~mW}$ \\
\hline Total & $15 \mathrm{~mW}$ average \\
\hline
\end{tabular}

In discussions that follow, we will use $20 \mathrm{~mW}$ of continuous power generation as a conservative power generation target. Local energy storage, probably in a supercapacitor, will allow periodic, short-duration periods of elevated power consumption. If conditions limit the amount of power that is available for prolonged periods, the frequency of data transmissions can be dynamically adjusted to reduce consumption.

-Station blackout risks constitute approximately $70 \%$ of the total safety risk for NPPs even if natural events (e.g., earthquakes, fires, and floods) are not considered [32]. 


\subsubsection{Environment}

The values for environmental parameters listed below were obtained from a preliminary safety analysis for a U.S.-designed commercial reactor [27] and seem consistent with other values found in literature. Values shown in Table 4 are the maximum expected for worst-case locations in primary and secondary containment. Because we are interested in the effects on enclosed electronics, radiation levels only for gamma and neutrons are of interest.

Table 4. Ambient environment for normal and accident scenarios

\begin{tabular}{|l|c|c|c|c|c|c|c|c|}
\hline \multirow{2}{*}{\begin{tabular}{c}
\multirow{1}{*}{$\begin{array}{c}\text { Operating } \\
\text { Scenario }\end{array}$} \\
\cline { 2 - 10 }
\end{tabular}} & \multicolumn{4}{|c|}{ Primary Containment } & \multicolumn{4}{c|}{ Secondary Containment } \\
\cline { 2 - 9 } & ${ }^{\circ} \mathrm{C}$ & $\%$ & $\mathrm{~Gy} / \mathrm{h}$ & $\mathrm{cm}^{-2} \cdot \mathrm{s}^{-1}$ & ${ }^{\circ} \mathrm{C}$ & $\%$ & $\mathrm{~Gy} / \mathrm{h}$ & $\mathrm{cm}^{-2} \cdot \mathrm{s}^{-2}$ \\
\hline $\begin{array}{l}\text { Normal } \\
\text { operations }\end{array}$ & 65 & 90 & 0.2 & $6 \mathrm{E} 4$ & 60 & 90 & 0.02 & low \\
\hline $\begin{array}{l}\text { Shutdown, } \\
\text { pumps operating }\end{array}$ & 65 & 90 & 0.2 & low & 60 & 90 & 0.02 & low \\
\hline $\begin{array}{l}\text { Cladding, RPV, } \\
\text { and pipe rupture }\end{array}$ & 170 & steam & $2 \times 10^{5}$ & low & 142 & steam & $2 \times 10^{3}$ & low \\
\hline
\end{tabular}

Temperatures and radiation levels for most locations in secondary containment will be substantially less severe than the levels shown in this table. In addition, the post-accident values are worst-case values that are expected soon after loss of system integrity. Radiation levels will start to decay significantly after a few hours. As a result, expected integrated gamma doses are probably of more interest in the case of an accident (Table 5).

Table 5. Integrated gamma dose for 6 months following loss-of-containment accident

\begin{tabular}{|c|c|c|}
\hline & Primary Containment & Secondary Containment \\
\hline Integrated $\gamma$ dose, Gy & $3 \times 10^{6}$ & $6 \times 10^{5}$ \\
\hline
\end{tabular}

\subsubsection{Electromagnetic Interference}

By definition, there will be no conducted electromagnetic interference (EMI) for a wireless sensor node. Good engineering practices and proper selection of wireless communications technology will ensure that there are no radiated interference issues for these low-power devices.

\subsection{TECHNOLOGY GAPS}

In this section, we evaluate the potential of previously identified energy harvesting technologies to meet the requirements for powering a WSN in a NPP environment.

\subsubsection{Radiant Energy Harvesters}

Ambient electromagnetic fields from natural and man-made sources permeate our environment, and they span the frequency spectrum from DC (e.g., Earth's magnetic field) to $10^{19} \mathrm{~Hz}$ (e.g., gamma

* Some isolated areas are listed as having higher radiation levels (near heat exchangers and demineralizers, for example). 
rays) and beyond. Current R\&D efforts focus on three technology areas for capturing this energy and converting it into electricity.

Electric-field (E-field) antennas - Electric fields in typical industrial or residential environments are simply too weak to power the target sensor node. As an example, consider how much energy could be collected from an 100,000 W omnidirectional FM radio transmitter $(100 \mathrm{MHz})$ at a distance of $400 \mathrm{~m}(1 / 4 \mathrm{mile})$ using a large, properly aimed rooftop yagi antenna (gain $=10 \mathrm{~dB}$ ). The voltage created across a matched $300 \mathrm{Ohm}$ load would be approximately $1.0 \mathrm{mV}$, yielding a power level less than $4 \mathrm{nW}$.

RF energy inside a power plant is usually considered a threat - not an asset. Exclusion zones around instrument stations keep sensitive electronics separated from walkie-talkies and cell phones unless detailed site-specific electromagnetic compatibility (EMC) surveys have demonstrated that such measures are not required [28]. Even before the widespread use of digital electronics in power plants, electromagnetic interference (EMI) from lightning, arc welders, generators, and other sources of electromagnetic stressors was responsible for, on average, a couple of instrument failures that rose to the level of licensee event reports (LERs) in the United States each year [29].

The availability even of weak RF fields during an accident scenario is also an issue. Events that would cause a plant to shut down (earthquakes, tornados, tsunamis, hostile actions, etc.) threaten not only the integrity of radio transmitter installations but also the availability of grid power necessary for their operation. Similarly, sources of RF energy within the plant would be likely to go off-line during a SBO.

Even though E-field harvesting is a fairly popular subject of current research efforts, it is not likely to produce technology useful for powering WSNs, especially in NPPs, in the foreseeable future.

Magnetic-field (B-field) antennas - The two issues that plague E-field collectors, low field strengths and lack of source continuity, also apply to magnetic field devices.

Magnetic fields can interfere with pacemaker operation, corrupt data stored on the stripes on credit cards, and induce "hum" in microphone cables; but fields strong enough for use in energy harvesting are rarely encountered. The most common source of the time-varying magnetic fields required to induce energy in a receiving coil is $60 \mathrm{~Hz}$ alternating current flowing through a power conductor. Even if the conductor is carrying hundreds of amps, it is not possible to gather sufficient energy from the surrounding field unless the receiving coil is in such intimate proximity to the power conductor that the wire loops actually surround it, as in the case of a current transformer.

Electrical motors and generators and their associated electronics can also be sources of significant magnetic fields. Although they are designed to contain their internal fields for the sake of high efficiency and low electromagnetic interference, some magnetic flux escapes into the nearby environment. However, even for very large motors such as those in propulsion systems for ships, field strengths measured several centimeters from the motor casing are on the same order of magnitude as the earth's magnetic field [30].

The availability of these time-varying magnetic fields depends on the availability of electricity, so no harvesting could be performed in the absence of grid power and back-up power. In addition, energy harvested in this manner is not really waste energy-it is energy "stolen" from functioning systems. Magnetic induction is being used in motion and vibration transducers that convert mechanical energy to time-varying magnetic fields through conductor coils. These devices are discussed in the Kinetic Energy Harvesters section below. 
Photovoltaic cells - Technology for indoor photovoltaic (IPV) energy converters is maturing and being used to wireless sensor networks, HVAC and lighting controls, and novelty items. Compared to a solar cell in direct sunlight, however, IPV harvesters typically exhibit only $0.1 \%$ of the output power per unit area. This dramatic difference is the result of reduced illumination levels (typically 500 lux vs. 100,000 lux) and illumination-dependent conversion efficiencies.

IPV cells typically produce only $10 \mu \mathrm{W} \cdot \mathrm{cm}^{-2}$ when exposed to typical office-level lighting, so a square cell array with sufficient capacity for our WSN module would be almost a half-meter on a side.

Availability of ambient light is a serious limitation in a NPP environment, especially during off-grid or SBO conditions. No direct sunlight is available inside secondary or primary containment, and artificial lighting levels are often reduced when operating on backup power. The tiny bit of illumination from emergency lights will disappear when their local batteries are drained.

Although it is among the most mature of power harvesting technologies, the obstacles to using IPV technology for self-powered sensor nodes seem insurmountable - even without considering radiationtolerance issues.

\subsubsection{Kinetic Energy Harvesters}

Vibration, motion, and flow transducers offer reasonable energy densities, and there are many sources of each available in an operating plant. All have issues, however, that would limit their usefulness for WSN applications.

Vibration transducers - Whether using piezoelectric, electrostatic, or magnetic induction devices, approximately $100 \mu \mathrm{W} \cdot \mathrm{cm}^{-3}$ can be obtained from vibration harvesters mounted on a surface vibrating with only $1 \mathrm{~m} \cdot \mathrm{s}^{-1}(0.11 \mathrm{~g})$ acceleration [31]. In such a location, a reasonably sized module $(2 \mathrm{~cm} \times 10 \mathrm{~cm} \times 10 \mathrm{~cm})$ could power our WSN. Without making measurements on pipes, equipment, and structures installed and functioning just as if they were in an operating plant, we can only speculate as to the availability of such surfaces. And, because vibration transducers operate over such narrow frequency ranges, the devices would have to be tailored to match their target locations, creating interchangeability and inventory concerns.

Even more of a barrier, however, is the availability of vibration sources in the absence of plant power. Even if vibration energy does not disappear entirely, the characteristics (in particular, the frequency content) of the energy might change so much that the transducers become useless.

Motion transducers - If robbing energy from moving equipment components such as rotating pump shafts is an acceptable approach, relatively large quantities of power can be captured with fairly simple devices. The gap in this scheme is access to parts that will still be moving in extended postaccident conditions. Diesel- or turbine-driven pumps might still be able to function in most accident scenarios [32], but they are so crucial to plant safety that operators will be reluctant to allow any piggy-backing on their moving parts.

Flow transducers - Tapping into energy from flowing fluids (water, steam, air, oil, etc.) in plant piping is intrusive, would require pipe penetrations, and, in most instances, would require transducers suited for very harsh service. (Transducers with moving parts would be unacceptable.) Air circulated by ventilation systems is a potential (but very low-density) source. Once more, energy harvested by these means is not waste energy - it is energy intended for other purposes. 
As with previously discussed approaches, the availability of these sources in SBOs is problematic. If no backup power is available, the only fluid flow occurring would be the result of thermal convection currents. We cannot envision a practical system that could gather a sufficient amount of energy from passive convection flow.

\subsubsection{Thermal Energy Harvesters}

Thermal harvesting seems to be an attractive approach because of the abundance of waste heat at NPPs. For every watt of electrical power produced, $2 \mathrm{~W}$ of waste heat must be dealt with [33]. Decay heat produced by a full set of fuel rods in a $1 \mathrm{GW}$ reactor averages to nearly a megawatt during an entire fueling cycle [34]. This heat continues to be produced when the reactor is shut down and even when the fuel assemblies are removed from service and placed in spent fuel storage pools. In SBO scenarios, heat is the one form of energy most likely to persist until grid or backup power can be restored.

Thermal energy harvesters capture heat energy flowing from a warm surface to a cooler surface and convert it to electricity. Familiar examples are in commercially available electronic wristwatches that consume only a couple of microwatts and can be powered by heat from the wearer's arm. However, our hypothetical WSN requires several orders of magnitude more power than these watches.

In our previous report [31], we identified two technologies, one well established and one under development, having the potential to meet these power requirements in a reasonably sized and cost-effective package. These technologies are discussed below.

Thermoelectric generators - Using commercially available technology, a thermoelectric generator approximately the size of a blackboard eraser could power the hypothetical WSN if mounted on a warm surface at least $50^{\circ} \mathrm{C}$ above ambient temperature. No penetration of reactor pipes or vessels would be required.

Thermoelectric materials have been demonstrated that can withstand temperatures much higher than those likely to be encountered in a NPP environment under any conditions. On the Department of Energy's 125 W Multi-Mission Radioisotope Thermoelectric Generator recently deployed on NASA's Mars rover Curiosity, the hot-side temperature ranges from 800 to $1,000^{\circ} \mathrm{C}$, depending on operating conditions [35].

Two technology gaps confront deployment of TEG harvesting technology in NPPs.

1. A demonstration that available thermoelectric materials can withstand radiation exposure accumulated during (at least) one fueling cycle and one accident scenario.

2. Identification of suitable hot surfaces inside secondary and primary containment that can accommodate TEGs or thermal interfaces (such as a passive heat pipes) for TEGs.

Appropriate surfaces would be kept hot by decay energy when the reactor is not operating, and they would be convenient to desired sensor locations. Neither installation of the device nor the small amount of heat removed from the contact area can impact reactor performance, reliability, or safety.

Pyroelectric generators - In addition to the two gaps listed above for TEGs, pyroelectric generation faces a technology maturity gap. Verified models show that a novel MEMS device [9] providing five times the energy density of thermoelectric generators can be made using well-established fabrication 
processes, but the technology has not yet been demonstrated on that scale. The pyroelectric material used in these devices can function at even higher temperatures than thermoelectric materials.

When this self-resonating pyroelectric converter technology reaches the market, it will be able to serve as a drop-in replacement for thermoelectric generation in a great majority of applications. Its higher energy density would allow, for instance, more frequent WSN data transmissions and/or more powerful transmitters.

\subsubsection{Supporting Electronics}

The design of the majority of the circuitry in a self-powered WSN (Figure 1) will be independent of the harvesting technology employed. The power management block would vary slightly according to the type of harvester used, but circuitry implementing the remaining functions would not.

The operating environment at the target location might dictate some circuit modifications, however. Within 2 years, radiation levels in some primary containment locations would result in accumulated doses higher than the tolerance thresholds for some semiconductor technologies-100 Gy of gamma and $10^{10} \mathrm{~N} \mathrm{~cm}^{-2}$. It might prove more cost-effective to design WSNs for use inside primary containment using more rad-tolerant (and expensive) semiconductor and supercapacitor technologies while using less exotic devices in WSN modules targeted for use in other areas.

Communications issues will be addressed in a future program task. R\&D is required to develop communications technologies needed to support greater data generation and transmission demands expected to accompany advancements in digital sensor, measurement, and control technologies while maintaining reliability, resiliency, and data security. RF attenuation through primary containment barriers needs to be characterized, transmission frequencies and power levels will be chosen to avoid interference with instrumentation and in-plant radio communications, encryption schemes will be studied, network architectures will be compared, and jamming-resistant technologies will be considered. 


\section{CONCLUSIONS}

Many industries are beginning to utilize mesh networks to replace conventional point-to-point wiring, reaping the cost savings associated with eliminating the communications cabling. In addition to these cost savings, these mess networks open the potential for greater expansion in instrumentation in the plant that could augment human performance, provide additional data on plant equipment and component status, and facilitate online assessment of the material condition of plants.

The use of wireless communications eliminates one set of wires. Additional cost savings are secured when the cabling associated with powering sensors is eliminated. The combination of wireless communications and power harvesting enables the implementation of truly wireless sensor nodes (WSNs). Development of methods to couple low-drift, high-accuracy, low-power transducers with ambient power harvesting to produce a transducer that is capable of being installed during construction of the plant and operating reliably for many years and possibly until the plant is decommissioned is needed.

Fortunately, NPP facilities are abounding with environmental energy sources having potential to power wireless sensor nodes. Of the harvesting technologies considered, all except thermal energy harvesting have known issues that make them unsuitable for use in the NPP environment-especially if operation through extended SBOs is desired. Identified technological gaps for these technologies are summarized in Table 6 . Issues considered to be insurmountable in the foreseeable future are marked with asterisks.

Two specific implementations of thermal energy harvesting, thermoelectric generators and selfresonating pyroelectric converters, are good candidates for further evaluation. If they prove able to handle the reactor environment and to be installed without compromising reactor operations, selfpowered WSNs for use in and around commercial NPPs will be a step closer to realization. These technologies will have to be tested under similar environmental conditions such as radiation and temperature prior to being used in a NPP. A demonstration of these power harvesting techniques powering wireless sensor nodes will be performed in a later phase.

Before these mesh networks can be used in NPPs, R\&D is needed to develop robust digital instrumentation communication techniques and architectures. Threats to reliable communication systems come from many sources including natural events, random failure of components, human error, physical intrusion, and cybersecurity breaches. The concepts of reliability, resiliency, and security constitute trustworthiness, which sustains the major functions of a communication system. While natural events, random failures, and human error can be addressed in the architecture of the communication system, all communicating systems are potentially vulnerable to intrusion and cybersecurity breaches. This vulnerability can be due to improper design or to an inadequate implementation of the design. Wired and wireless networks face similar vulnerabilities to attacks but do have differences in the attack vectors. Wired networks can have distant attackers but can have adequate perimeter defenses. Wireless networks — given only wireless access - must be within the range of the attacker's wireless device to be vulnerable. Guaranteeing the integrity of safetysignificant functions and ensuring the necessary communications reliability pose challenges and requires $\mathrm{RD} \& \mathrm{D}$ to address. Communications requirements and the development of a concept for operation for sensor networks in NPPs will be investigated in FY 2013. 
Table 6. Implementation gaps for power harvesting technologies in nuclear plant environment

\begin{tabular}{|c|c|c|}
\hline Energy Type & $\begin{array}{l}\text { Exploitation } \\
\text { Technology }\end{array}$ & Implementation Obstacles \\
\hline \multirow{3}{*}{ Radiant } & Photovoltaic conversion & $\begin{array}{l}\text { Interior light levels are marginal } \\
\text { Ambient light might not persist during SBO* }\end{array}$ \\
\hline & E-field collection & $\begin{array}{l}\text { Ambient fields are too weak* } \\
\text { Fields might not persist during SBO* }\end{array}$ \\
\hline & B-field collection & $\begin{array}{l}\text { Ambient fields are too weak* } \\
\text { Fields might not persist during SBO* }\end{array}$ \\
\hline \multirow{3}{*}{ Kinetic } & Vibration transduction & $\begin{array}{l}\text { Suitable vibration sources have not been identified } \\
\text { Different transducers would be required for different } \\
\text { vibration sources } \\
\text { Vibrations might change character or might not persist } \\
\text { during SBO* }\end{array}$ \\
\hline & Motion transduction & $\begin{array}{l}\text { Conversion devices are intrusive, most have moving parts } \\
\text { Energy harvested is not waste energy } \\
\text { Motion might not persist during SBO* }\end{array}$ \\
\hline & Flow transduction & $\begin{array}{l}\text { Energy harvested is not waste energy } \\
\text { Converters with adequate capacity are intrusive, have } \\
\text { moving parts } \\
\text { Flow might not persist during SBO* }\end{array}$ \\
\hline \multirow[b]{2}{*}{ Thermal } & $\begin{array}{l}\text { Thermoelectric } \\
\text { generation }\end{array}$ & $\begin{array}{l}\text { Adequate radiation tolerance must be established } \\
\text { Suitable heat sources must be identified } \\
\text { Mounting surface will be cooled slightly }\end{array}$ \\
\hline & Pyroelectric generation & $\begin{array}{l}\text { Adequate radiation tolerance must be established } \\
\text { Suitable heat sources must be identified } \\
\text { Mounting surface will be cooled slightly } \\
\text { Technology maturation is required to reach potential } \\
\text { capacity }\end{array}$ \\
\hline
\end{tabular}




\section{WORKS CITED}

[1] K. Korsah and et al., "Instrumentation and Controls in Nuclear Power Plants: An Emerging Technologies Update, CR-6992,” Nuclear Regulatory Commission, Washington, D.C., 2009.

[2] B. Kaldenbach and et al., "Assessment of Wireless Technologies and Their Application an Nuclear Facilities, CR-6882," Nuclear Regulatory Commission, Washington, D.C., 2006.

[3] R. Allan, "Energy Harvesting Powers Industrial Wireless Sensor Networks," Electronic Design, pp. 22-29, 20 September 2012.

[4] A. Horn, R. James, D. Ture, and W. Victor, "Assessment of Existing Plant Instrumentation for Severe Accident Management, TR-103412," Electric Power Research Institude, Palo Alto, California, 1993.

[5] S. Chalasani and J. Conrad, "A Survey of Energy Harvesting Sources for Embedded Systems," in IEEE Southeastcon, Huntsville, Alabama, 2008.

[6] T. Galchev, J. McCullagh, R. Peterson, and K. Najafi, "Harvesting Traffic-Induced Bridge Vibrations," Journal of Micromechanics and Microengineering, 21(10), 104005 (2001).

[7] IDTechEx, "Pedestrians to Power Walkway to London 2012 Olympic Park," EnergyHarvestingJournal.com, vol. n/a, no. n/a, p. web page, 2012.

[8] "Water Power Program: History of Hydropower," U.S. Department of Energy, 19 September 2011. [Online]. Available: http://www1.eere.energy.gov/water/hydro_history.html [Accessed 23 September 2012].

[9] S. Hunter, N. Lavrik, S. Mostava, S. Rajic, and P. Datskos, "Review of Pyroelectric Thermal Energy Harvesting and New MEMS-Based Resonant Energy Conversion Techniques," in SPIE - Energy Harvesting and Storage: Materials, Devices, and Applications III, Baltimore, Maryland, 2012.

[10] R.-R. Fan, Z.-Q. Tian, and Z. L. Wang, "Flexible Triboelectric Generator," Journal of Nano Energy, 1, 324-328 (2012).

[11] S. Roundy and E. Leland, "Improving Power Output for Vibration Based Energy Scavengers," Pervasive Computing, pp. 28-36 (2005).

[12] M. Defosseux and M. B. S. Marzencke, "Piezoelectric vibration harvesting device with automatic resonace frequency tracking capability," Materials Research Society Proceedings, vol. 1218, no. Z07, 2009.

[13] A. Salehi-Khojin, Vibration Analysis of Piezoelectric Microcantilever Sensors, Clemson University, Clemson, South Carolina, 2008.

[14] L. Laursen, "Acoustic Energy Harvesters Gaining Volume," IEEE Spectrum On-Line, April 2011.

[15] G. Min, "Thermoelectric Energy Harvesting," in Energy Harvesting for Autonomous Systems, Norwood, Artech House, 2010, pp. 135-157.

[16] K. Buddharaju, N. Singh, G. Lo, and S. Lee, "Chip-Level Thermoelectric Power Generators Based on High-Density Silicon Nanowire Array Prepared with Top-Down CMOS Technology," IEEE Electron Device Letters, 32(5), 674-676 (2011).

[17] Y. Li, "Improved Vertical Silicon Nanowire Based Thermoelectric Power Generator with Polyimide Filling," IEEE Electron Device Letters, 33(5), 715-717 (2012).

[18] J. Klett, "High Thermal Conductivity, Pitch-Based Carbon Foam for Thermal Management Applications," in 22nd Annual Conference on Ceramic, Metal, and Carbon Composites, Materials, and Structures, Cocoa Beach, Florida, 1998. 
[19] S. Hunter and P. Datskos, MEMS-Based Pyroelectric Thermal Energy Scavenger, Oak Ridge National Laboratoruy, UT-Battelle, 2010.

[20] A. Nasiri, S. Zabalawi, and G. Mandic, "Indoor Power Harvesting Using Photovoltaid Cells for Low-Power Applications," IEEE Transactions on Industrial Electronics, 56(11), 4502-4509 (2009).

[21] T. J. Kamierski and S. Beeby, Energy Harvesting Systems: Principles, Modeling and Applications, Springer, New York, 2010.

[22] M. Raju and M. Grazier, "Energy Harvesting, White paper \#SLYY018A," Texas Instruments, Dallas, Texas, 2010.

[23] B. Atwood, B. Warneke, and K. S. J. Pister, "Smart Dust Mote Forerunners," in Proceedings of the 14th Annual International Conference on Microelectromechanical Systems, Interlaken, Switzerland, 2001.

[24] L. Miller, N. Emley, P. Shafer, and P. Wright, "Strain Enhancement with Cantilevered, Piezoelectric MEMS Vibrational Energy Scavenging Devices," University of California Berkeley, Berkeley, 2008.

[25] M. T. Panella-Lopez and M. Gasulla-Forner, Harvesting, Powering Autonomous Sensors: An Integral Approach with Focus on Solar and RF Energy, Springer, New York, 2011.

[26] ZigBee Alliance, ZigBee Specification, Document 053474r17, ZigBee Standards Organization, San Ramon, California, 2008.

[27] Taiwan Power Company, "Lungmen Units \#1 and \#2 Preliminary Safety Analysis Report," Taiwan Nuclear Energy Council, New Taipei City, Taiwan, 2007.

[28] P. F. Keebler, "Eliminating the Need for Exclusions Zones in Nuclear Power Stations," Electric Power Research Institute, Knoxville, Tennessee, 2012.

[29] A. C. Gehl and E. W. Hagen, Aging Assessment of Reactor Instrumentation and Protection System Components, NUREG/CR-5700, Nuclear Regulatory Commission, Washington, D.C., 1992.

[30] A. A. Adam, S. Korolu, and H. Gulez, "Stray Electromagnetic Field Distribution around Permanent Magnet Synchronous Motor Drive,” pp. 1782-1787, 2009.

[31] D. A. Clayton, W. H. Andrews, R. Lenarduzzi, and D. Wall, State of the Practice for Power Harvesting, Oak Ridge National Laboratory, Oak Ridge, Tennessee, 2012.

[32] S. Eide, D. Gentillon, T. Wierman, and D. Rasmuson, Reevaluation of Station Blackout Risks at Nuclear Power Plants, CR-6890, Vol. 2, Nuclear Regulatory Commission, Washington, D.C., 2005.

[33] World Nuclear Association, "Cooling Power Plants (http://www.worldnuclear.org/info/cooling_power_plants_inf121.html)," World Nuclear Association, London, U.K., 2011.

[34] M. Tilghman, “Using Nuclear Waste Heat as Power Source," Stanford University, Stanfor, CA, 2012.

[35] J.-P. e. a. Fleurial, "Thermoelectrics: From Space Power Systems to Terrestrial Waste Heat Recovery Applications," in NASA 2011 Thermoelectrics Applications Workshop, San Diego, California, 2011.

[36] D. M. Bagnall and S. A. Boden, "Photovoltaic Energy Harvesting," in Energy Harvesting for Autonomous Systems, Norwood, Artech House, 2010, pp. 45-90.

[37] S. Beeby and N. White, "Kinetic Energy Harvesting," in Energy Harvesting for Autonomous Systems, Norwood, Artech House, 2010, pp. 91-134. 
[38] H. Kim, Y. Tadesse and S. Priya, "Piezoelectric Energy Harvesting," in Energy Harvesting Technologies, New York, Springer, 2009, pp. 3-39.

[39] I. Ayala, D. Zhu, M. Tudor, and S. Beeby, "Autonomous Tunable Energy Harvester," PowerMEMS, 2009, pp. 49-52.

[40] S. Priya and D. Inman, Energy Harvesting Technologies, Springer, New York, 2008.

[41] G. J. Snyder, "Thermoelectric Energy Harvesting," in Energy Harvesting Technologies, New York, Springer, 2009, pp. 325-336.

[42] Y. Li, K. Buddharaju, N. Singh, G. Lo, and S. Lee, "Chip-Level Thermoelectric Power Generators Based on High-Density Silicon Nanowire Array Prepared with Top-Down CMOS Technology," IEEE Electron Device Letters, 32(5), 674-676 (2011).

[43] S. Hunter, N. Lavrik, S. Rajic, and P. Datskos, Pyroelectric Thermal Energy Harvesting using MEMS based Resonant Structures, Oak Ridge National Laboratory, Oak Ridge, Tennessee. 



\section{APPENDIX A. ENERGY HARVESTING TECHNOLOGIES BACKGROUND}

This appendix summarizes the physical principles of often-encountered technologies employed in energy harvesting devices.

\subsection{TRANSDUCERS OF RADIANT ENERGY}

Two approaches are used to convert radiant energy into electrical energy: photovoltaic cells and antennas. Photovoltaic cells are used to harvest visible light, while antennas extract energy from RF or power-frequency electromagnetic fields.

\subsubsection{Natural and Artificial Visible Light}

Photovoltaic cells are used to convert energy from visible light into electrical energy. They operate most efficiently in intense, broad-spectrum light such as bright sunlight. The most important feature of a photvoltaic cell is a junction between p-type and an n-type semiconductor materials (see Figure 7) that can be reached by incident light (photons).
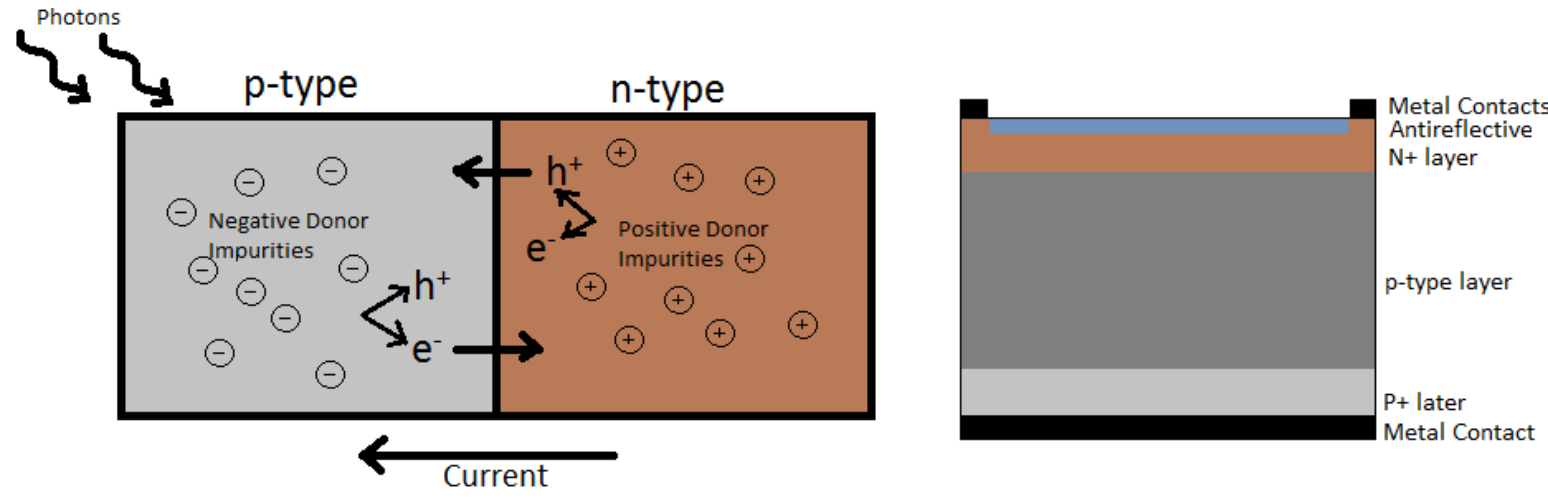

Figure 7. Semiconductor junction and the typical layer design for a PV cell.

When a photon in an appropriate energy range reaches one of the semiconductor materials, it will excite an electron, creating an electron-hole carrier pair. If this happens in the bulk of the material, the pair will quickly recombine and emit a photon, and no electrical energy is created. However, if the impact occurs very near the interface between the two materials, carriers will cross the junction before they recombine, and they cannot return - the junction exhibits a rectifying behavior. The resulting charge imbalances cause the p-type material to become negatively charged and the n-type material to become positively charged. When connected to an appropriate electrical circuit, current flows and energy can be dissipated.

A typical cell structure consists of several layers (Figure 7). The top surface is often coated with a thin film antireflective surface, so that less light is lost to reflection. The contacts on the top are small metal fingers which allow light to reach the semiconductors, while the bottom contact is a solid metal layer. Individual cells are usually place together in a module, linked in series, in order to attain a 
usable amount of voltage. The size of the module (number of constituent cells) is determined by the requirements of the device it is powering.

In a circuit, a photovoltaic cell can be represented as a current source in series with a diode. Given that the charge carrier injection due to photons creates a current $\mathrm{I}_{\mathrm{L}}$, then the net current through this equivalent circuit would be

$$
I=I_{0}\left(e^{\frac{q V}{k T}}-1\right)-I_{L}
$$

In the above, $I_{0}$ is the reverse saturation current, $\mathrm{k}$ is the Boltzmann constant, and $T$ is the temperature.

The transferal of solar energy to electrical energy is limited by to the Carnot efficiency, just as thermoelectric devices. However, the sun is much warmer than conventional heat sources. Estimates of the greatest achievable efficiency put it at roughly $93.3 \%$ (over a temperature difference of more than $5500 \mathrm{~K}$ ). However, a variety of loss sources mean that photovoltaic cells have only achieved efficiencies of roughly $5 \%$ to $22 \%$ [36].

There are numerous types of photovoltaic cells, and each has advantages and disadvantages. The most common primarily utilize silicon. Single-crystal and multicrystalline silicon devices are very mature, and commercially available modules have reached efficiencies of up to $22 \%$, while more costly and high-end devices such as the PERL (passivated emitter, rear locally diffused) have attained efficiencies up to $25 \%$. These high-end cells feature an inverted pyramid texture pattern on their surface, which decreases reflectiveness and increases absorption lengths. Amorphous silicon devices are considerably cheaper. While they cannot achieve efficiencies on par with single-crystal or multicrystalline devices, they are very well suited to low expense indoor implementations. Other silicon-based cell technologies include thin film polycrystalline silicon and multijunction silicon. Non-silicon cell technologies are less common and tend to be less efficient. Some of these technologies include Cadmium Telluride/Cadmium Sulphide cells, Copper Indium (Gallium) Disselenide cells, Single Junction III-V cells, and Multijunction III-V cells. More experimental photovoltaic methods also exist. These devices are based on less mature technologies and have not yet reached efficiencies above $10 \%$. Dye-sensitized cells are based around the incomplete intermixing of p-type and n-type materials. Organic Polymer cells are based on organic semiconductor materials. Inorganic Bulk-Heterojunction cells are still very experimental and are centered on the use of nanowires. However, this method has demonstrated enough promise that it is being pursued by researchers [36].

\subsubsection{Ambient Magnetic Fields}

The guiding principle related to magnetic induction is Faraday's law of induction,

$$
\mathcal{E}=-\frac{d \Phi_{\mathrm{B}}}{d t}
$$

which states that the open-loop (no-load) voltage, $\mathcal{E}$, created in a loop of wire is equal the rate of change of magnetic flux, $\Phi_{\mathrm{B}}$, passing through the area enclosed by the loop.

The source of the time-varying magnetic flux might be a permanent magnet which varies either in position or orientation (or both) relative to the receiving (secondary) loop. Or, it might be a nearby 
(primary) electrical conductor carrying current which generates a field according to Ampere's law, simplified here to describe the magnetic field around a long, straight conductor in free space.

$$
B=\frac{\mu_{\mathrm{o}}}{2 \pi r} I
$$

where $B$ is the magnetic flux density, $I$ is the instantaneous current in the conductor, $r$ is the distance from the center of the conductor, and $\mu_{\mathrm{o}}$ is the magnetic permeability of free space. Higher primary current produces higher flux density at the location of the secondary coil.

If the secondary coil has $N$ loops of wire that enclose the same area, then the voltages from individual loops add linearly:

$$
\mathcal{E}=-N \frac{d \Phi_{\mathrm{B}}}{d t}
$$

Matters get more complicated if one tries to draw energy from the coil. The self-inductance of the receiving coil becomes important as current flows through it. The efficiency of the coupling between the source and the receiving coil depends not only on the distance between the source and the secondary coil and their relative orientations but also on the electrical properties of the conductor and on the magnetic characteristics of all nearby materials. In general, the amount of energy extracted from the secondary coil can be increased by the following.

- Increasing the strength of the source

- Optimizing the position and orientation of the receiving coil in to maximize the difference between minimum and maximum captured fluxes

- Increasing the rate of change of captured magnetic flux

- Using lower-resistance material for the secondary coil

- Increasing the magnetic permeability of intervening materials

- Matching the electrical impedance of the load to the output impedance of the source/secondary configuration

- Optimizing the number of turns in the secondary coil

Increasing the number of loops in the secondary coil will not always increase output power. Selfinductance, impedance matching, and electrical resonances must all be taken into consideration.

Two types of loops are commonly used for magnetic field antennas: resonant loops and small loops. In a resonant-loop antenna (Figure 8), the circumference of the loop is an integral number (usually 1) of wavelengths of the field being captured (assuming a periodically varying field). A capacitor is added at the connection of the antenna leads to the loop to tune the receiving circuit to the same frequency. 


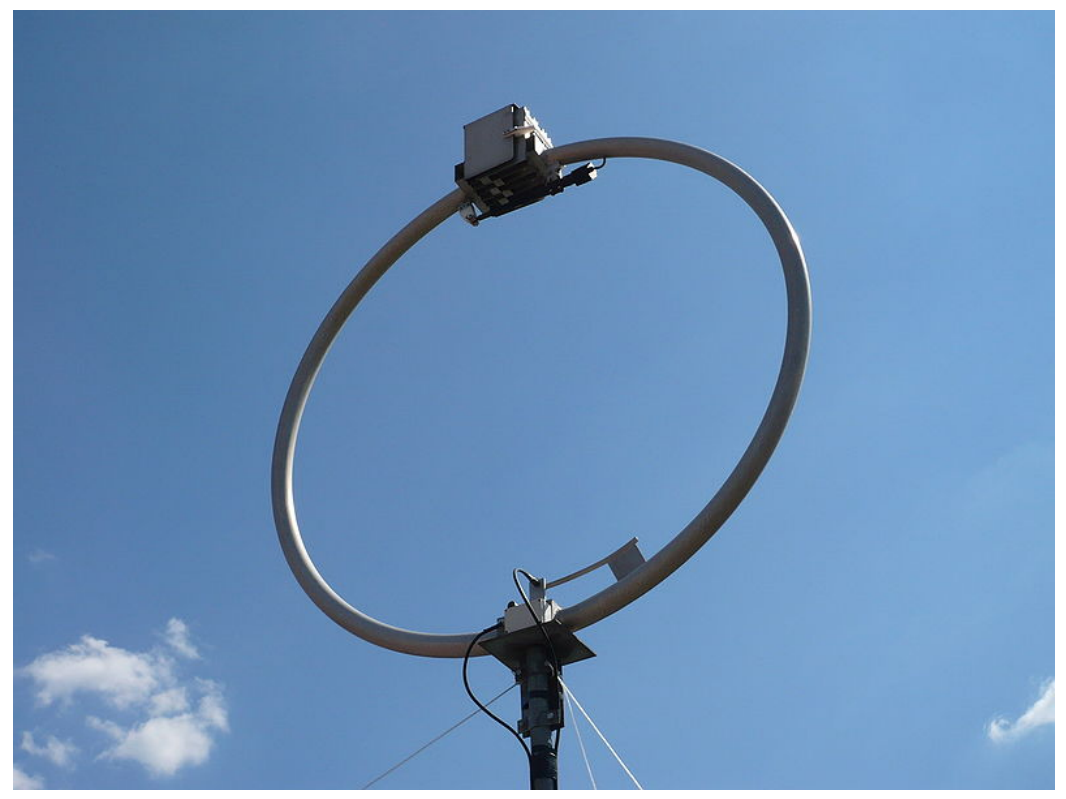

Figure 8. A resonant-loop antenna tuned for short-wave reception

(Source: Wikipedia Commons).

Because the magnetic flux from a current-carrying conductor is perpendicular to the direction of field propagation, these loops capture maximum flux when the coil plane is oriented perpendicular to an RF source.

Small-loop antennas have circumferences less than $10 \%$ of the wavelengths of interest. They usually feature a large number of loops wound around a high-permeability ferrite core (Figure 9).

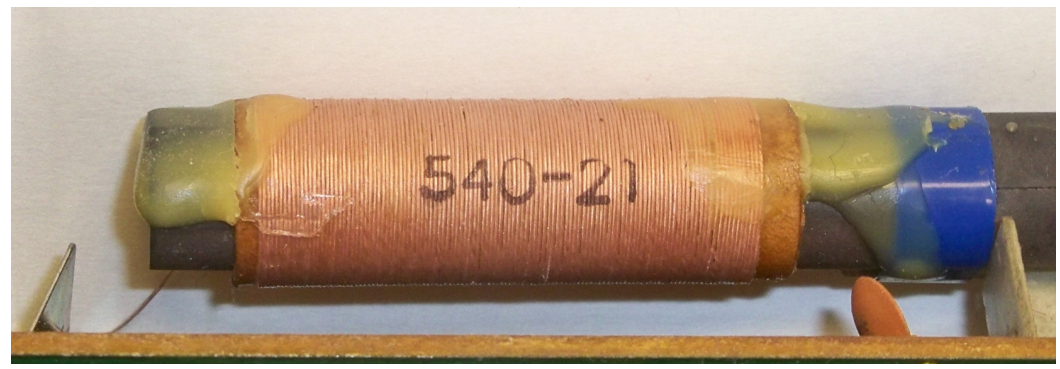

Figure 9. Ferrite rod antenna.

The ferrite material concentrates flux inside the coils and increases voltage output. At higher frequencies, depending on the ferrite material used, hysteresis losses in the core material become significant. The high permeability of ferrite material also increases the inductance of the coil. Antennas used for radio reception are usually wound using very fine wire, so DC resistance of the wire and high-frequency skin effects would make these antennas unsuitable for most power harvesting applications.

A small-loop antenna can be tuned to a certain frequency range by connecting a capacitor across its leads. 
Except for areas extremely close to power transmission lines or radio transmitting antennas, ambient magnetic fields are so small that harvesting significant amounts of energy would require impractically large and expensive devices. Consider a scenario where intimate proximity to a high-power source is exploited. A single-phase, $13.8 \mathrm{kV}$ power transmission line feeding a subdivision of 200 homes, each consuming an average of $5 \mathrm{~kW}$, would carry 72.5 Amps. If one of the power conductors were threaded through a typical current transformer consisting of many loops of wire wound on a toroidal ferrite core and delivering $50 \mathrm{mV} / \mathrm{A}$ into a $50-\mathrm{Ohm}$ load, only $72 \mathrm{~mW}$ of power would be generated.

Scavenging power from power distribution lines without such intimate proximity is even more daunting. Because the sum of the currents flowing in the two or three conductors in a transmission line is very close to zero, the strength of the net magnetic field drops off very quickly as distance to the closest conductor increases - much faster than the inverse-with-distance relationship for a long, straight conductor.

A more promising approach for magnetic induction harvesting involves extracting kinetic energy from motion or vibration and using it to vary the spacing between a permanent magnet and a pickup coil. Tapping into natural and man-made motion sources in this manner is currently an area of intense research.

\subsubsection{Ambient Electrical Fields}

Linking of energy between conductors via electric fields is capacitive coupling. The capacitance between two conductors is determined by the surface area of the conductors, the proximity and orientation of the surfaces, and the electrical characteristics of material between and around the conductors. For the simple case of two same-sized, flat, parallel conductive plates having surface area $\mathrm{A}$ and separation $d$ and the space between them filled with a material having dielectric constant $\epsilon$, capacitance (Figure 10) is given by

$$
C=\epsilon \frac{\mathrm{A}}{d}
$$

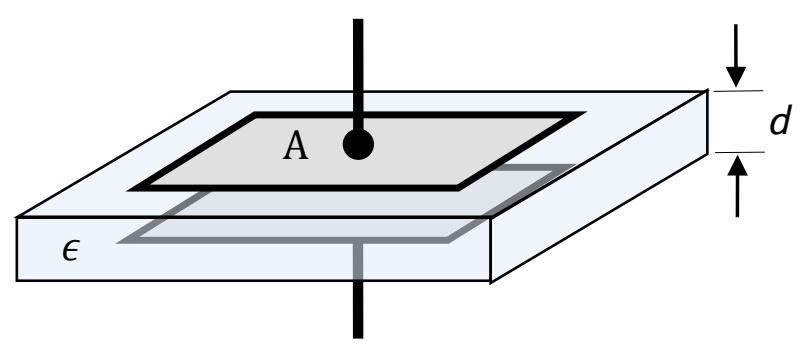

Figure 10. Parallel-plate capacitor.

The energy stored in a capacitor having voltage $\boldsymbol{V}$ between its plates is

$$
W=\frac{1}{2} C \boldsymbol{V}^{2} \text {. }
$$

To avoid confusion, the variable $W$ is often used as the variable for stored energy because $E$ often represents electromotive force (voltage). The energy stored in the capacitor is equal to the net work 
done in charging it, thus the $W$.

If a time-varying voltage $\boldsymbol{V}(\boldsymbol{t})$ is impressed on capacitor plates, electrical current will flow through the capacitor according to

$$
\boldsymbol{I}=C \frac{d \boldsymbol{V}(t)}{d t}
$$

Alternatively, current can be created by holding the voltage across the plate constant and varying the capacitance by altering the distance between the plates, the relative orientation of the plates, the average dielectric constant of the material between the plates, etc.

$$
\boldsymbol{I}=\boldsymbol{V} \frac{d c(t)}{d t} .
$$

Attempts to scavenge energy by placing a "receiving" conductor in the electrical field from a "transmitting" conductor, such as a power line or a radio transmitter, are likely to be disappointing. As in the case of inductive coupling, the field strengths at convenient (and safe!) distances from the sources are weak enough that gathering in more than a few milliwatts would require large, expensive systems.

As an example, consider how much energy one could collect from a 100,000 W omnidirectional FM radio transmitter $(100 \mathrm{MHz})$ at a distance of $400 \mathrm{~m}(1 / 4 \mathrm{mile})$ using a large, properly aimed rooftop yagi antenna $($ gain $=10 \mathrm{~dB}$ ). The voltage created across a matched $300 \mathrm{Ohm}$ load would be $1.02 \mathrm{mV}$, yielding a power level less than $4 \mathrm{nW}$ !

However, as is also the case for inductive coupling, research into small-scale devices that use kinetic energy to modulate electric fields using variable-geometry circuit components is among the most promising ongoing harvesting technology development areas.

\subsection{TRANSDUCERS OF KINETIC ENERGY}

Three major kinetic harvesting methods indicated in the report (piezoelectric, electromagnetic, and electrostatic) will be elaborated on here.

\subsubsection{Vibration and Motion Transducers}

Most vibration-based harvesters rely on a cantilever structure with a suspended mass that oscillates out of phase with the harvester's environment. The transduction mechanism takes advantage of this relative motion to generate a current. This structure can be modeled as a second-order spring-mass system (Figure 11), as can structures for many large motion transducers. 

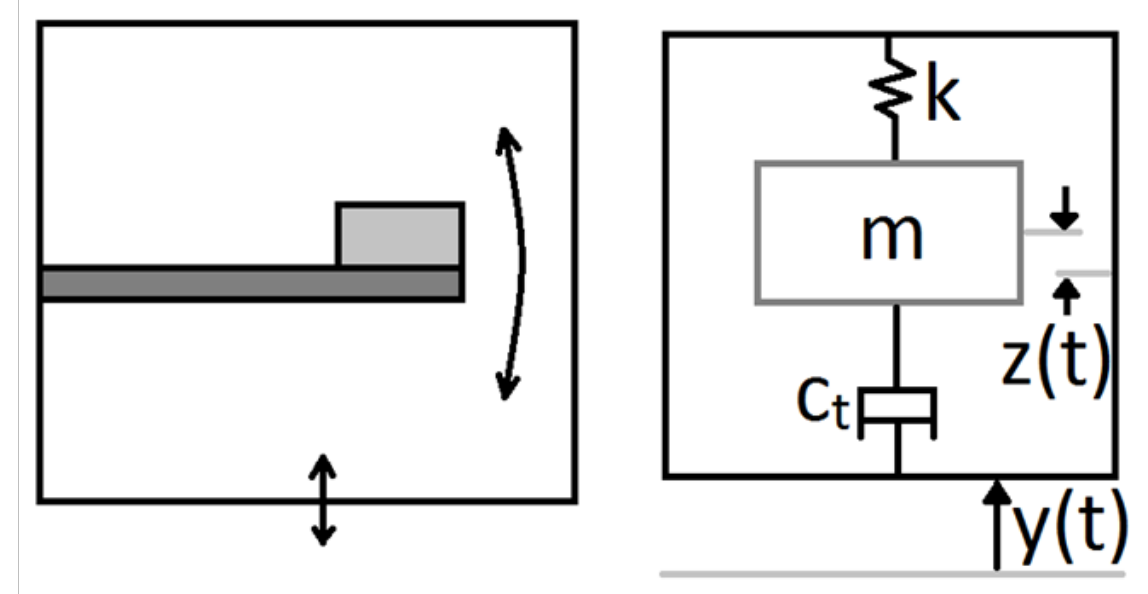

Figure 11. Cantilever structure and spring-mass model.

Assuming that the mass on the cantilever is far smaller than the mass of the frame, then the differential equation of motion for the above system is

$$
m \ddot{z}(t)+c \dot{z}(t)+k z(t)=-m \ddot{y}(t) .
$$

The natural frequency of the system $\left(\omega_{n}\right)$ is given by

$$
\omega_{n}=\sqrt{k / m} \text {. }
$$

Maximum displacement (and power output) is attained when the harvester is driven at this natural frequency. The maximum available power depends on the system's transducer damping ratio $\left(\zeta_{e}\right.$; damping ratios indicate the ratio of system damping to critical damping) and the parasitic damping ratio $\left(\zeta_{p}\right)$, as well as the amplitude of the environmental vibration $(\mathrm{Y})$ :

$$
P_{\max }=\frac{m * \zeta_{e} * \omega_{n} * Y}{4 *\left(\zeta_{p}+\zeta_{e}\right)^{2}}
$$

$\mathrm{P}_{\max }$ is greatest when the two damping ratios are equal.

Energy directly generated by vibration harvesters is always in the form of an alternating current [37] [38].

Electrostatic Vibration Harvesters: Electrostatic vibration harvesters differ slightly from harvesters using other transduction methods. They more often rely on a comb-like structure, rather than a single cantilever (Figure 12). Further, the harvester can either cycle the distance between a capacitor's plates, or the degree to which those plates overlap. 


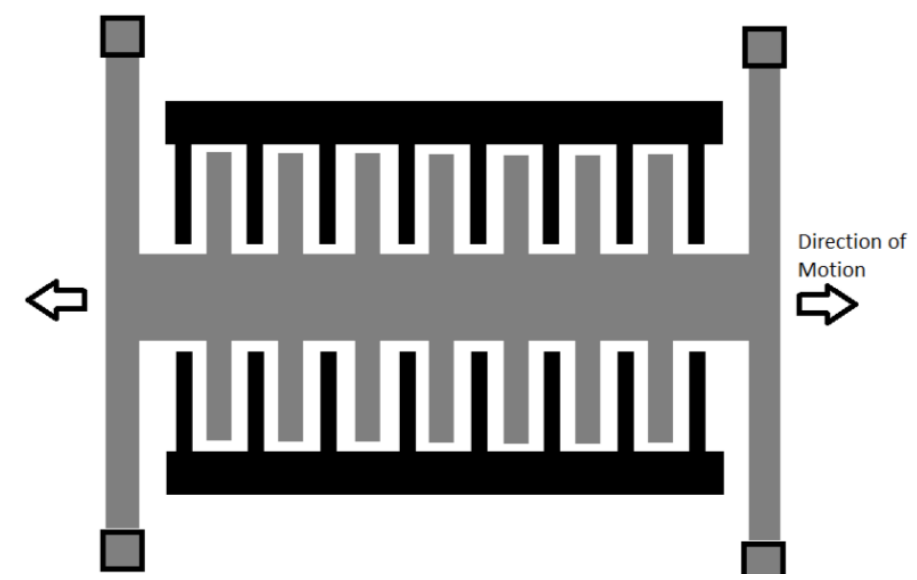

Figure 12. An example of an electrostatic vibration harvester: the electrostatic comb transducer.

The harvester must also hold either voltage or current constant, so that the change in capacitance can be used to generate power. If the generator is voltage constrained, the charge will vary with capacitance. Voltage constraint is achieved by charging the capacitor to its maximum voltage $\left(V_{\max }\right)$ with a charge reservoir, while the plates are at their closest $\left(C_{\max }\right)$. As the plates move apart, capacitance decreases to a minimum $\left(C_{\mathrm{min}}\right)$, and excess charge returns to the reservoir. The energy gathered from this process is given:

$$
E=\frac{1}{2}\left(C_{\max }-C_{\min }\right) V_{\max }{ }^{2}
$$

This method generally produces more energy but requires more complex electronics. If the generator is charge constrained, the voltage varies with capacitance. Charge constraint can be achieved by charging the capacitor to a starting voltage $\left(V_{\text {START }}\right)$, with the plates again at their closest. Without a charge reservoir, as the plates draw apart and capacitance decreases to $C_{\min }$, voltage will increase to $V_{\max }$. The energy yielded in this way can be determined with

$$
E=\frac{1}{2}\left(C_{\max }-C_{\min }\right) V_{\max } V_{\min }
$$

The initial charge for a voltage constrained varactor can come from a reservoir that is then removed from the circuit, or from electret materials. This method does not produce as much energy but is simpler to implement. In both cases, it is important that the voltage always remain below the acceptable voltage for attached electronics.

The electronic damping coefficient for a gap varying electrostatic generator can be directly determined with

$$
c_{e}=\frac{Z * Q^{2}}{4 * N_{g} * \varepsilon_{0} * t * l} .
$$

In the above, $Q$ is the charge on the plates, $N_{g}$ is the number of gaps between fingers, $t$ is the device thickness, $l$ is the finger length, and $z$ is the displacement amplitude [37].

Piezoelectric Vibration Harvesters: Piezoelectric vibration harvesters typically consist of a piezoelectric layer that is bonded to the surface of the cantilever; some designs feature a cantilever 
that is mostly composed of piezoelectric material. As the cantilever bends, this layer is tensioned and compressed, resulting in an AC current. The electrical damping coefficient for a piezoelectric oscillator can be determined given electromechanical coupling factor $(k)$, the resistive electrical load $\left(R_{L O A D}\right)$, the load capacitance $\left(C_{L O A D}\right)$, the mass $(m)$, and the system's natural frequency $\left(\omega_{n}\right)$ :

$$
c_{e}=\frac{2 m \omega_{n}{ }^{2} k^{2}}{\sqrt{\omega_{n}^{2}+1 /\left(R_{\text {load }} C_{\text {load }}\right)^{2}}} .
$$

As they rely on the strain produced by vibration on the cantilever itself, piezoelectric generators can benefit from non-rectangular cantilever shapes. Trapezoidal shapes ensure that the entire structure is stressed more uniformly, while a split cantilever greatly increases overall strain [11].

Magnetic Induction Vibration Harvesters: Vibration harvesting using varying magnetic fields is based on Faraday's law of electromagnetic induction. An overview of the theory involved is presented in Section 8.1.2. In most cases, a magnet is mounted on a spring or a cantilever so that system vibration changes the distance and/or relative orientation between the magnet and a pick-up coil.

Vibration Harvester Tuning: Vibration-based harvesters must operate at a frequency that matches the natural frequency of their cantilever system. If they are subject to vibrations that are not within a small range of this frequency, they will not produce a meaningful output. In order for it to provide a good output, a harvester must either be designed with a specific frequency (and therefore a specific location) in mind, or it must be capable of being tuned after construction. A great deal of research has been dedicated to achieving a larger range of operational frequencies for vibration harvesters.

The most technically simple of methods to grant a larger frequency range is to create a harvester with an array of multiple cantilever arms, each of which has a different resonant frequency. This is the easiest method to implement. However, the extra cantilevers add to the volume of the device, while the output is no different from a single cantilever harvester that is operating at its resonant frequency.

Frequency range can also be increased by creating a tunable harvester. Tuning mechanisms can accomplish their goal in several ways. Mechanical tuning alters the mechanical properties of the system, such as the effective length of the cantilever, or the cantilever's stiffness. The resonant frequency of a cantilever with known dimensions (length $l$, width $w$, height $h$ ) can be determined given the Young's modulus $(E)$ of the cantilever material, the cantilever's mass $\left(m_{c}\right)$, and the mass at the end of the cantilever $(m)$ [37]:

$$
f=\frac{1}{2 \pi} \sqrt{\frac{E w h^{3}}{4 l^{3}\left(m+0.24 m_{c}\right)}} .
$$

A method of accomplishing stiffness alteration is to apply an axial load: tension or compression along the length of the cantilever beam. An example is a device with a tuning magnet attached to the end of the cantilever. By moving the mobile base magnet closer or further away from the end of the cantilever, the effective damping of the system can be altered [39]. This device, designed by Ayala et al. [39], then utilized a mobile magnet attached to the base to tune the harvester. A CAD drawing of the electromagnetic device is shown, along with a picture depicting the completed device [39]. 
For tuning by axial load, the new modified frequency can be determined, given the frequency before the load is applied $\left(f_{0}\right)$, the buckling force of the cantilever $\left(F_{b}\right)$, and the axial load $(F)$ :

$$
f_{\text {new }}=f_{0} \sqrt{1+\frac{F}{F_{b}}} .
$$

Tuning can also be accomplished electrically. By altering the electrical load on the system, the electrical damping can be altered, which will in turn change the system's natural frequency. This method of tuning has only been accomplished with piezoelectric vibration harvesters, by altering a capacitive load [37].

Tuning mechanisms, if poorly implemented, can have a negative impact on device effectiveness. The mechanism itself consumes energy, and care must be taken to ensure that the tuning mechanism does not take more energy to operate than it can contribute to the device's output. In particular, active selftuning can consume a sizable portion of the harvester's output, and should only be used if it is expected that the device will need to deal with a varying environmental vibration frequency. The frequency "resolution" must also be considered. If the tuning mechanism is too imprecise, it will be relatively useless.

Piezoelectric Harvesters: Harvesters utilizing the piezoelectric effect generally consist of a piezoelectric element that is bonded to a structure that undergoes deformation. The amount of energy taken from this deformation directly depends on the material that is used. Two constants associated with specific materials determine the effectiveness of a piezoelectric substance (Figure 13). The electromechanical coupling coefficient $(\mathrm{k})$ denotes the amount of strain a material will experience given an applied electromagnetic field $(\mathrm{m} / \mathrm{V})$. The piezoelectric constant indicates the open circuit charge density given an applied force $(\mathrm{C} / \mathrm{N})$.

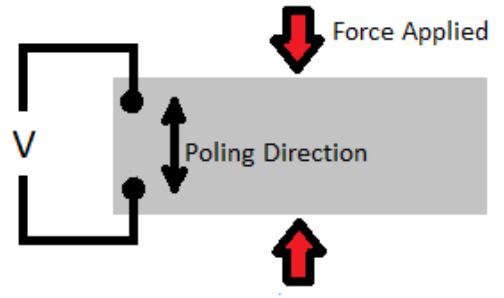

33 Mode: $d_{33}, k_{33}$

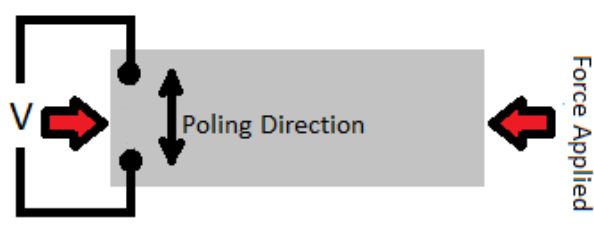

31 Mode: $d_{31}, k_{31}$

Figure 13. Piezoelectric strain modes.

Electrode placement that causes the direction of strain to be parallel to the polarization of the element will be able to take advantage of greater electromechanical coupling coefficients ( $k_{33}$ instead of $\left.k_{31}\right)$ and piezoelectric constants $\left(\mathrm{d}_{33}\right.$ instead of $\left.\mathrm{d}_{31}\right)$ [38].

While some single-crystal materials, such as quartz, exhibit piezoelectric properties, piezoceramics and polymers exhibit the best performance. Some of the best materials fall under the category of ceramics. Lead zirconate titanate (PZT) materials are particularly effective, with piezoelectric constants and electromechanical coupling coefficients that are several times greater than those of other materials. Quartz crystals, however, can operate at much higher temperatures. 
The piezoelectric capabilities of these materials degrade with age and utilization. Aging is roughly logarithmic with time; however, straining the materials increases the aging rate. In general, softer materials will degrade more quickly than harder materials. However, harder materials also tend to have lower piezoelectric constants and electromechanical coupling coefficients [37].

\subsection{TRANSDUCERS OF THERMAL ENERGY}

\subsubsection{Thermoelectric Generators}

Thermoelectric generators (TEGs) generate power from the difference in temperature between two surfaces. This is accomplished by using the Seebeck effect. A common implementation of the Seebeck effect is to create a junction between two dissimilar metals and allow this junction to be heated. A more effective method is to place a pair of p-type and n-type semiconductors electrically in series and thermally in parallel to create a thermocouple (Figure 14).

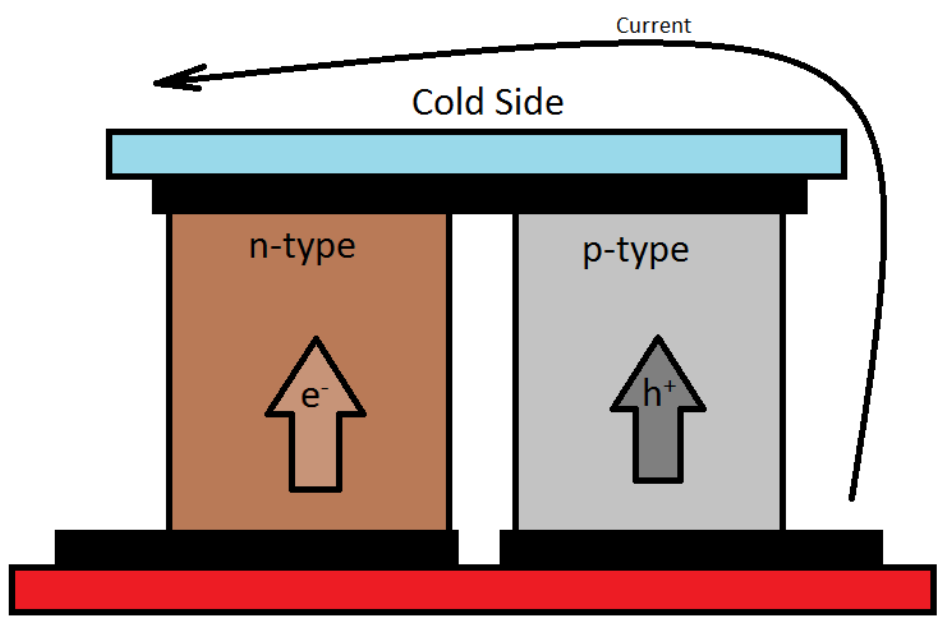

Hot Side

Figure 14. A thermocouple.

The charge carriers (electrons, or $\mathrm{e}^{-}$, for the $\mathrm{n}$-type and holes, or $\mathrm{h}^{+}$, for the $\mathrm{p}$-type) in each semiconductor will tend to migrate away from the warm side of the thermocouple. This results in a current. A single TEG can consist of hundreds of thermocouples connected in series.

Any thermoelectric device is limited to a certain maximum theoretical efficiency, known as the Carnot efficiency ( $T_{h}$ is the hot side temperature, and $T_{c}$ is the cold side temperature) [15]:

$$
\eta_{\text {carnot }}=\frac{T_{h}-T_{c}}{T_{h}}
$$

The implication is clear: a greater difference between the hot side temperature and the cold side temperature will yield a greater efficiency. However, this represents an ideal device, and real efficiencies tend to be only a fraction of the Carnot efficiency (generally around 10-20\%) [40]. Some materials are more effective for thermoelectric devices than others. They can be rated using the Dimensionless Thermoelectric Figure of Merit $(z T)$, which depends on the material's electrical 
conductivity $(\sigma)$, its thermal conductivity $(\lambda)$, its Seebeck Coefficient $(\alpha)$, and temperature $(T$, in Kelvin) [41]:

$$
z T=\frac{\alpha^{2} * \sigma * T}{\lambda}
$$

Because $z T$ varies with temperature as well as with the material used, material selection for a TEG can depend on the intended temperature range. The most common material used in TEGs is bismuth telluride $\left(\mathrm{Bi}_{2} \mathrm{Te}_{3}\right)$, which achieves a maximum $z T$ of roughly 1 at just above room temperature. Some of the best regularly achieved $z T$ values are attained with a bismuth telluride/lead telluride superlattice, reaching almost 2 at around $300 \mathrm{~K}$. Silicon germanium (SiGe) can operate at very high temperatures, retaining a $z T$ value of 1 at almost $1200 \mathrm{~K}$ [15]. On the microscale, experiments have also been conducted in utilizing silicon nanowires as thermocouple material. This has led to $z T$ values approaching 1, with more improvement possible [42].

The efficiency and power output of a thermoelectric generator also depends on how the thermal resistance of the thermoelectric element compares with the combined resistances of the TEG's heat source and heat sink. If the thermal resistance of the source or sink is high, then the thermoelectric element's resistance must also be high; otherwise, there will be little temperature change across the it. However, if the thermal resistances of both the source and sink are low, then the thermoelectric element's resistance must also be low, so that a meaningful amount of heat can flow through it [15] [41].

\subsubsection{Pyroelectric Cantilever}

Pyroelectric materials can be used to harvest power from temporal changes in temperature. When a pyroelectric material is heated or cooled, the degree of spontaneous polarization of the molecules within it changes, as does the amount of charge on capacitor plates bonded to the material. A change in charge on a fixed capacitor held at a fixed voltage produces a current through a connected load. Repeated heating and cooling of the material generates an AC current through the load.

In most environments, ambient temperature changes occur so slowly that the amount of energy harvestable from these small, slowly changing currents is too small to be useful. A novel device [9] exploits a difference in temperature between two surfaces to create a rapidly changing thermal environment for a small layer of pyroelectric material, resulting in a power generation density that compares favorably with any thermoelectric implementation.

In the self-resonating pyroelectric converter (Figure 15), a multi-layered cantilever is in weak thermal contact (through its pedestal) with a relatively cool mounting surface. As the cantilever structure cools, an aluminum/silicon dioxide bimorph structure bends so that a thermally conductive mass at the end of the cantilever comes into contact with the warmer surface. The entire cantilever warms up quickly, causing the structure to flex in the opposite direction so that the tip mass contacts the cool surface. The cantilever loses its heat to the cold surface and snaps back to contact the warmer surface once again, setting up a mechanical oscillation that repeats as long as there is an appropriate temperature difference between the two surfaces. Oscillation frequencies in excess of $200 \mathrm{~Hz}$ are projected. 


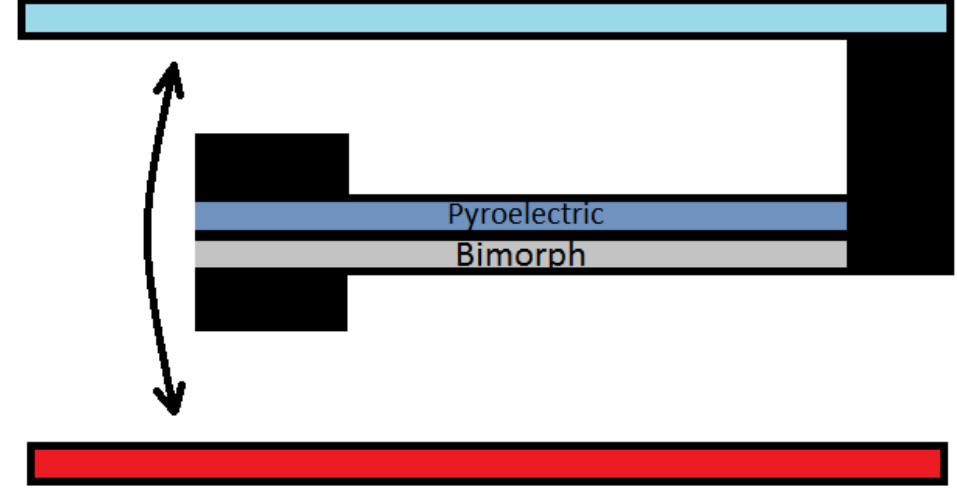

Hot Side

Figure 15. A pyroelectric bimorph cantilever.

A layer of pyroelectric material is in intimate thermal contact with the bimorph materials so that it is heated and cooled along with the cantilever structure. Metal films on its surfaces serve as capacitor plates and are connected through electrical leads to an external load. A small part of the energy collected is used to bias the capacitor plates to optimize generation efficiency.

The output of this pyroelectric converter can be determined given the applied bias voltage $\left(V_{a}\right)$, capacitor surface area (A), and the material's pyroelectric coefficient (p) [43]:

$$
P(t)=\Delta V_{a} I_{p}(t)=\Delta V_{a} A p \frac{d T}{d t}
$$

Modeling of the thermodynamic properties of these structures, confirmed by tests on early prototypes, projects that efficiencies up to $80 \%$ of the Carnot maximum are achievable using this technology. (The relatively mature thermoelectric generation technology is leveling out at $25 \%$ of theoretical efficiency for similar temperature differentials.) Because some pyroelectric materials continue to function at temperatures in excess of $1400 \mathrm{~K}$ (vs. less than $1300 \mathrm{~K}$ for thermoelectric materials), Carnot efficiencies can be higher as well [19]. 